\title{
DSD-1-Proteoglycan Is the Mouse Homolog of Phosphacan and Displays Opposing Effects on Neurite Outgrowth Dependent on Neuronal Lineage
}

\author{
Jeremy Garwood,, Oliver Schnädelbach, ${ }^{1}$ Albrecht Clement, ${ }^{1}$ Katrin Schütte, ${ }^{1}$ Alfred Bach, ${ }^{3}$ and \\ Andreas Faissner ${ }^{1,2}$ \\ 1Department of Neurobiology, University of Heidelberg, INF 364, 69120 Heidelberg, Germany, ${ }^{2}$ Laboratoire de \\ Neurobiologie du Développement et de la Régénération (LNDR), UPR 1352 Centre de Neurochimie du Centre National de \\ la Recherche Scientifique et Université Louis Pasteur (ULP), 67084 Strasbourg, France, and ${ }^{3 B A S F-L Y N X ~ B i o s c i e n c e, ~}$ \\ INF 515, 69120 Heidelberg, Germany
}

DSD-1-PG is a chondroitin sulfate proteoglycan (CSPG) expressed by glial cells that can promote neurite outgrowth from rat embryonic mesencephalic (E14) and hippocampal (E18) neurons, an activity that is associated with the CS glycosaminoglycans (GAGs). Further characterization of DSD-1-PG has included sequencing of peptides from the core protein and the cloning of the corresponding cDNA using polyclonal antisera against DSD-1-PG to screen phage expression libraries. On the basis of these studies we have identified DSD-1-PG as the mouse homolog of phosphacan, a neural rat CSPG. Monoclonal antibodies $3 \mathrm{H} 1$ and 3F8 against carbohydrate residues on rat phosphacan recognize these epitopes on DSD-1-PG. The epitopes of the antibodies, L2/HNK-1 and L5/Lewis-X, which have been implicated in functional interactions, are also found on DSD-1-PG. Although DSD-1-PG has previously been shown to promote neurite outgrowth, its upregulation after stab wounding of the CNS and its localization in regions that are considered boundaries to axonal extension suggested that it may also have inhibitory functions. Neonatal dorsal root ganglion (DRG) explants grown on a rich supportive substrate (laminin) with and without DSD-1-PG were strikingly inhibited by the proteoglycan. The inhibitory effects of DSD-1-PG on the DRG explants were not relieved by removal of the CS GAGs, indicating that this activity is associated with the core glycoprotein. The neurite outgrowth from embryonic hippocampal neurons on laminin was not affected by the addition of DSD-1$P G$. This indicates that DSD-1-PG/mouse phosphacan can have opposing effects on the process of neurite outgrowth dependent on neuronal lineage.

Key words: DSD-1-proteoglycan; phosphacan; chondroitin sulfate proteoglycan; neurite outgrowth; hippocampus; dorsal root ganglion
Extracellular matrix (ECM) molecules are expressed in many regions of the developing nervous system where they are thought to play crucial roles in neural development, being implicated in processes such as neuronal adhesion, shape, migration, and neurite outgrowth (Lander and Calof, 1993; Letourneau et al., 1994; Faissner and Steindler, 1995; Fitch and Silver, 1997). Although the organization of the ECM in the vertebrate CNS is not well understood it is marked by the relative abundance of chondroitin sulfate proteoglycans (CSPGs) and hyaluronan (Maleski and Hockfield, 1997; Rauch, 1997).

\footnotetext{
Received Dec. 15, 1998; revised March 2, 1999; accepted March 8, 1999.

This work was supported by the German Research Council (DFG SFP GLIA Fa 159/5-1,2,3), the International Spinal Research Trust (ISRT), a Schilling Professorship for Neuroscience to A.F., and Friedrich-Ebert-Stiftung and DFG Graduiertenkolleg Zelluläre and Molekulare Neurobiologie stipends to O.S. J.G.is the grateful recipient of a Centre National de la Recherche Scientifique Poste Rouge. We thank Claudia Mandl and Daniela Schnörr for technical assistance, Professor Dr. W. Huttner for ongoing support, Drs. F. Lafont and J. Trotter for comments on this manuscript, Thomas Brugger (ZHV/B-A30, BASF AG, Ludwigshafen, Germany) for the peptide sequencing, and Dr. D. Barthels for the gift of cDNA libraries.

Correspondence should be addressed to Dr. A. Faissner, Department of Neurobiology, University of Heidelberg, Im Neuenheimer Feld 364, 69120 Heidelberg, Germany.

Dr. Schnädelbach's present address: Physiological Laboratory, Downing Street, University of Cambridge, Cambridge CB2 3EG, UK.

Dr. Clement's present address: Ludwig Institute for Cancer Research, University of California at San Diego, La Jolla, CA 92093.

Dr. Schütte's present address: Procter \& Gamble Eurocor, Temselaan 100, B-1853, Strombeek-Bever, Belgium.

Copyright (C) 1999 Society for Neuroscience $\quad 0270-6474 / 99 / 193888-12 \$ 05.00 / 0$
}

CSPGs, a heterogeneous set of proteins bearing glycosaminoglycans (GAGs) of the chondroitin sulfate (CS) class, account for most of the "soluble" proteoglycans in the brain (Lander, 1993). During development, strong immunostaining for CS often localizes to territories thought to act as barriers to migrating neurons or extending axons such as the roof plate and midline dorsal tectum (Snow et al., 1990b; Katoh-Semba et al., 1995), the posterior sclerotome (Oakley and Tosney, 1991; Landholt et al., 1995), and the dorsal root entry zone and dorsal columns in the spinal cord (Pindzola et al., 1993). In vitro CSPGs (Snow et al., 1990a; Dou and Levine, 1994; Maeda and Noda, 1996), the isolated core proteins of CSPGs (Dou and Levine, 1994; Maeda and Noda, 1996), and CS by itself (Snow et al., 1990a; SmithThomas et al., 1994) have also been shown to inhibit cell migration or neurite outgrowth on defined growth-promoting substrata.

Yet, it is clear that tissues that express CS do not always exclude the entry of axons, and in some cases CS staining coincides with developing axon pathways (Sheppard et al., 1991; Bicknese et al., 1994; McAdams and McLoon, 1995). Indeed, several in vitro studies suggest that CSPGs (Streit et al., 1993; Faissner et al., 1994), CS (Lafont et al., 1992; Fernaud-Espinosa et al., 1994), and isolated core proteins (Iijima et al., 1991) can promote rather than inhibit neurite outgrowth.

The mouse neural CSPG, DSD-1-PG, was originally identified by the monoclonal antibody (mAb) $473 \mathrm{HD}$, which specifically recognizes the CS epitope DSD-1 (Faissner, 1988; Faissner et al., 
1994). DSD-1-PG promotes neurite outgrowth from rat embryonic mesencephalic (E14) and hippocampal (E18) neurons, a process that is dependent on the DSD-1 GAG epitope, because it can be blocked specifically by the mAb 473HD or by enzymatic digestion of the CS GAGs (Faissner et al., 1994). The DSD-1 epitope has been shown to be sulfation-dependent and to correlate with CS D motifs (Clement et al., 1998). In cerebellar cultures, it is expressed on the surface of immature glial cells where it is downregulated with ongoing maturation, and it is not expressed on neurons (Schnädelbach et al., 1998). The developmental distribution of DSD-1-PG has been found to correspond to regions related to the formation of axonal trajectories such as the interrhomberic boundaries in chick, which is consistent with a role in growth promotion (Heyman et al., 1995), but it has also been found at glial barrel field boundaries in the developing mouse somatosensory cortex, which neurons do not cross (Steindler et al., 1995).

Several studies have reported the enhanced expression of growth-inhibiting CSPGs in the context of CNS lesions (McKeon et al., 1991; Bovolenta et al., 1993; Pindzola et al., 1993; Lips et al., 1995), and DSD-1-PG is also strongly upregulated after wounding in the CNS (Laywell et al., 1990; Laywell and Steindler, 1991; Barker et al., 1996; Deller et al., 1997). Such an upregulation of DSD-1-PG in the wound reaction might be attributable to the action of TGF- $\beta$ based on studies of Oli-neu, an oligodendrocyte precursor cell line (Schnädelbach et al., 1998).

Additional in vitro studies of the effects of DSD-1-PG on neurite outgrowth have been made, and we report here an inhibitory activity of DSD-1-PG on dorsal root ganglion (DRG) explants. Further biochemical characterization of DSD-1-PG is also presented, together with the cloning of the cDNA corresponding to the core protein and its identification as the mouse homolog of phosphacan.

\section{MATERIALS AND METHODS}

Antibodies and immunohistochemistry. Rat mAb 473HD and the rabbit polyclonal antibody (pAb) KAF13 were described previously (Faissner, 1988; Faissner et al., 1994). 473HD, a rat mAb, should not be confused with another mAb called 473 , from mouse, which also recognizes a CS epitope on a rat neural CSPG (Kosaka et al., 1992). mAbs 3F8, 3H1, and 2B49 against phosphacan and phosphacan-KS are available from the Developmental Studies Hybridoma Bank (University of Iowa, Department of Biological Sciences, Iowa City, IA). mAbs L2/HNK-1 (clones 334, rat IgM), L3 (clone 492, rat IgM), L4 (clone 483, rat IgM), and L5 (clone 487, rat IgM) have been described previously (Kruse et al., 1984; Kücherer et al., 1987; Streit et al., 1990). Western blots were performed as described and developed with peroxidase-derivatized secondary antibodies using the ECL kit (Amersham Buchler GmbH, Braunschweig, Germany) according to the manufacturer's instructions. Iodination and immunoprecipitation of DSD-1-PG were performed as described previously (Faissner et al., 1994).

Protein purification and deglycosylation studies. The DSD-1-PG was purified from detergent-free physiological saline-buffered brain lysates from postnatal day (P) 7-14 mice as described previously using a combination of affinity chromatography with the mAb 473HD bound to Sepharose resin, and anion-exchange chromatography (Faissner et al., 1994). It was quantitated using the protein assay (Bio-Rad Laboratories, Munich, Germany) or the Micro BCA reagent (Pierce, Rockford, IL) and by the determination of uronic acid equivalents (Blumenkrantz and Asboe-Hansen, 1973). The DSD-1-PG was deglycosylated in the presence of protease inhibitors (Faissner et al., 1994) using chondroitinase ABC (ChABC) (EC 4.2.2.4; Boehringer Mannheim GmbH, Mannheim, Germany) at $50 \mathrm{mU} / \mathrm{ml}$ in $40 \mathrm{~mm}$ Tris, $\mathrm{pH} 8,40 \mathrm{~mm}$ sodium acetate, $0.01 \% \mathrm{BSA}$ for $2 \mathrm{hr}$ at $37^{\circ} \mathrm{C}$, and keratanase (EC 3.2.1.103; Seikagaku Kogyo, Tokyo) at $100 \mathrm{mU} / \mathrm{ml}$ in $50 \mathrm{~mm}$ Tris, $\mathrm{pH} \mathrm{7.4,} \mathrm{for} 2 \mathrm{hr}$ at $37^{\circ} \mathrm{C}$.

Protein sequencing. Purified DSD-1-PG was digested with ChABC and run out on a $4-10 \%$ SDS-PAGE. Because of the poor staining of DSD-1-PG, the Coomassie brilliant blue band corresponding to the core glycoprotein was excised based on alignments with adjacent lanes that were either silver-stained or blotted and detected with KAF13. The gel band was then rinsed in water to remove acetic acid, crushed, and incubated overnight at $37^{\circ} \mathrm{C}$ in $0.1 \mathrm{M}$ sodium hydrogen carbonate, $\mathrm{pH} 8.3$, with either $1 \mathrm{U}$ sequencing grade trypsin (Boehringer Mannheim) or subtilisin (Sigma, Munich, Germany) at $37^{\circ} \mathrm{C}$ for $24 \mathrm{hr}$. The resulting peptides were recovered from the gel pieces by extraction with acetonitrile and concentrated in a lyophilizer. The peptides were then loaded on a reverse-phase HPLC (RP-HPLC) nanobore column in $1 \%$ aqueous trifluoroacetic acid and separated by RP-HPLC using an increasing acetonitrile gradient. This yielded a number of peptides from which the $\mathrm{N}$-terminal amino acid sequence was obtained by Edman degradation using a protein sequencer (Applied Biosystems Sequencer 477A/494; Applied BioSystems, Foster City, CA).

Screening of cDNA expression libraries. Several mouse brain $\lambda$ cDNA expression libraries were screened using the pAb KAF13 at $1 \mu \mathrm{g} / \mathrm{ml}$, following standard procedures. The libraries used were BALB/c neonatal whole-brain oligo-dT and random-primed Uni-ZAP XR 1 (Stratagene GmbH, Heidelberg, Germany), C57/BL6 neonatal and adult whole-brain oligo-dT-primed $\lambda$ gt11, and C57/BL6 neonatal cerebellum (P2-6) oligodT-primed $\lambda$ gt11 (Barthels et al., 1988). The DNA sequence of the positive clones was obtained using the $\mathrm{Cy} 5$ AutoRead sequencing kit and the ALFexpress DNA sequencing system (Pharmacia Biotech, Freiburg, Germany). After screening of 3 million recombinant phages, three positive clones were obtained: TB24 and p159, which correspond to bases 1144-1509 and 1032-3591, respectively, of the cDNA sequence shown in Figure 2, and p166, which is the short, spliced form of receptor protein tyrosine phosphatase (RPTP) $\beta / \zeta$ with bases $1186-2392$ of the phosphacan sequence, the splice site, and then bases $4951-7850$ of the rat RPTP $\beta / \zeta$ cDNA sequence (RN09357 in the EMBL database) corresponding to the entire transmembrane domain, two tyrosine phosphatase domains, and 800 bases of the $3^{\prime}$ untranslated region of the RPTP $\beta / \zeta$ sequence. A Marathon cDNA amplification kit (Clontech, Heidelberg, Germany) was used to generate a P7 cerebellum cDNA library from $1 \mu \mathrm{g}$ poly $\left(\mathrm{A}^{+}\right)$RNA. The $5^{\prime}$ end of the sequence was obtained from this cDNA library using RACE (rapid amplification of cDNA ends) PCRs with specific primers based on the sequence of clone p159, and $5^{\prime}-$ priming from an adaptor sequence ligated to the cDNA. The PCR products were subcloned into plasmid pCR 2.1 (Invitrogen, Leek, The Netherlands) and sequenced. Once the $5^{\prime}$ end was known, the sequence was verified by PCR amplification using specific 5' primers and sequencing the corresponding PCR products. At the $3^{\prime}$ end, an expressed sequence tag (EST) clone, MM1180153 (EMBL database), was identified by sequence comparison of the rat sequence with computer DNA databases. This EST clone was obtained from the IMAGE consortium (RZPD, Berlin, Germany) and on sequencing was found to correspond to the entire $3^{\prime}$-untranslated region (4945-6782). Specific primers from this clone and clone p159 were used to generate the intervening $3^{\prime}$ sequence (3510-5064) from the cDNA library using PCR. The sizes of mRNAs corresponding to the clone $\mathrm{p} 159$ were investigated by Northern blotting using $\mathrm{P} 7$ cerebellum poly $\left(\mathrm{A}^{+}\right)$RNA and the Church method.

Cell culture. Hippocampal cell cultures were established from embryonic day 18 (E18) rat brains as described previously (Faissner et al., 1994; Kempf et al., 1996). Briefly, the hippocampi were obtained by microdissection and dissociated in supplemented N2 medium (Banker and Cowan, 1977). The resulting cell suspension was plated on coverslips at a density of 10,000 cells $/ \mathrm{cm}^{2}$ in supplemented N2 medium. DRG explants from P0 or P1 mice were prepared as described previously (Götz et al., 1996). Briefly, the ganglia were placed in HBSS on ice, and tissue and nerve fibers sticking to the explants were removed (Seilheimer and Schachner, 1988). Whole ganglia were transferred into culture medium consisting of DMEM medium supplemented with $2 \mathrm{mM}$ L-glutamine, 15 $\mathrm{ng} / \mathrm{ml}$ nerve growth factor (Sigma), and $20 \mu \mathrm{M}$ arabinosylcytosine (Sigma). These two neurite outgrowth model systems were chosen for analysis because they have been well characterized and standardized in our laboratory for a range of conditions. Although the hippocampal neurons are from rat and the DRG explants are from mouse, the interspecies differences are not very pronounced between rat and mouse. For these reasons it seemed adequate to use them for studies of the effects of DSD-1-PG as a substrate on poly-ornithine and laminin, respectively. There is in fact an extensive literature demonstrating the wide-ranging cross-species effects of extracellular matrix components, for example concerning laminin-1 or fibronectin, which are isolated from outdated human plasma or Engelbreth-Holm-Swarm-tumor tissue, respectively, 
and nevertheless used for neurons from various species, with comparable results.

Neurite outgrowth assays. Neurite outgrowth of E18 hippocampal neurons plated on supports was conducted as described previously (Lochter et al., 1991; Faissner et al., 1994; Götz et al., 1996). In brief, glass coverslips were treated with $1.5 \mu \mathrm{g} / \mathrm{ml}$ poly-DL-ornithine (PORN; Sigma) in $0.1 \mathrm{M}$ borate buffer, $\mathrm{pH} 8.2$, for $1 \mathrm{hr}$ at $37^{\circ} \mathrm{C}$ in a humidified atmosphere. Laminin (laminin-1 from Engelbreth-Holm-Swarm mouse sarcoma cells; Boehringer Mannheim) was subsequently coated at $5 \mu \mathrm{g} / \mathrm{ml}$ in $50 \mu \mathrm{l} \mathrm{PBS}$ per coverslip for at least $1 \mathrm{hr}$ at $37^{\circ} \mathrm{C}$ in the incubator, and the coverslips were washed twice with PBS before E18 hippocampal neurons were plated at $10,000 \mathrm{cells} / \mathrm{cm}^{2}$. DSD-1-PG was coated at $5 \mu \mathrm{g}$ uronic acid equivalents per milliliter. After coating, the Petri dishes were washed three times with PBS and blocked by incubation with $0.25 \%$ BSA for $2 \mathrm{hr}$. After $24 \mathrm{hr}$ of culture, neurons were stained for tubulin using an $\mathrm{mAb}$ to $\alpha$-tubulin (clone DM 1A; Sigma) as described previously (Götz et al., 1996). The quantitative morphometry and statistical analysis of neurite outgrowth were as described previously. Neurite outgrowth was determined as the fraction of process-bearing cells from at least 100 neurons per coverslip chosen at random and given in percentage. The morphometric analysis of neurite lengths was performed with the system Quantimet 500 MC (Leica, Bensheim, Germany) by measuring neurons with a process longer than one neuronal cell body. At least three independent experiments were analyzed, and the data were evaluated using nonparametric statistics. The distribution of the longest neurites was compared using the Mann-Whitney $U$ test; the mean values of sums of the longest neurites were compared by $t$ test. P0/P1 mouse DRG explants were grown in tissue culture plastic Petri dishes $(3 \mathrm{~cm}$ diameter) (Nunc, Wiesbaden, Germany) coated with PORN, laminin, and purified DSD-1-PG as described above. At least 10 explants were plated per dish. After $48 \mathrm{hr}$ the DRG cultures were fixed for $1 \mathrm{hr}$ by the addition of glutaraldehyde directly to the culture medium to a final concentration of $2.5 \%(\mathrm{v} / \mathrm{v})$, then the explants were stained with toluidine blue (Götz et al., 1996). The extent of neurite outgrowth was determined by measuring the neuritic halo around the explants. Neurite-bearing explants were defined as those bearing neurites longer than the diameter of the explant. ChABC (Boehringer Mannheim) digestion of the plated substrate was performed with $50 \mathrm{mU} / \mathrm{ml}$ in $40 \mathrm{~mm}$ Tris, $\mathrm{pH} 8,40 \mathrm{~mm}$ sodium acetate, $0.01 \% \mathrm{BSA}$ at $37^{\circ} \mathrm{C}$ for $2 \mathrm{hr}$, and the extent of digestion was confirmed by monitoring loss of the DSD-1 CS epitope using the 473HD mAb in an ELISA assay. The integrity of the protein substrate after ChABC digestion was confirmed using a pAb against laminin.

\section{RESULTS}

\section{Peptide sequences from DSD-1-PG correspond to phosphacan, and screenings of brain cDNA expression libraries with DSD-1-PG antiserum yield phosphacan clones}

Further characterization of the primary structure of DSD-1-PG entailed the obtention of peptide sequences from the core protein, together with the screening of mouse brain cDNA expression libraries using a polyclonal antiserum raised against DSD-1-PG.

A large number of peptide sequences corresponding to the protein sequence of the secreted rat CSPG phosphacan (Maurel et al., 1994) were obtained from proteolytic fragments of the purified DSD-1-PG (Fig. 1), suggesting that DSD-1-PG may be the mouse equivalent of this protein. This observation was supported by our screening of several bacterially expressed mousebrain cDNA phage libraries using the pAb KAF13, which was previously raised against the purified DSD-1-PG (Faissner et al., 1994). On Western blots, the antiserum preferentially recognizes the ChABC-digested core protein rather than whole PG (Fig. 4), and hence during screening it should recognize protein epitopes corresponding to the protein core. The three positive clones that we obtained on stringent screening of $3 \times 10^{6}$ phages were found to correspond to the mouse homologs of phosphacan and the corresponding transmembrane $\operatorname{RPTP} \beta / \zeta$. The cloning of the mouse phosphacan cDNA shown in Figure 2 was completed using

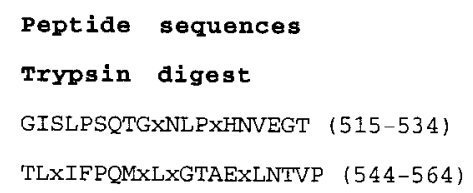

\section{subtilisin digest}

KFPLXMXVYXxxAD (148-161)

TVEXIVF (243-249)

ERPXVXY (333-339)

QIRKXEPQV (453-461)

SXPSQT (517-522)

DVLKPGST (628-635)

TXQPVY (757-761)

PLXPFSXAXFXXXMFR (826-841)

SAXFXSEMFRH (832-842)

GIKPLS (1045-1050)

PEXIFXVQ (1127-1134)

GXPXVEQ (1218-1224)

TGLPXL (1358-1363)
STDKYXI (224-230)

KDTVXI (250-255)

NEXXTGLNXG (437-446)

EFXTEXGIXLPXQ (509-521)

FIxPQM (546-551)

AFXPXSRPLDLAPXIN (735-750)

FPLATXLXXDNQXL (776-789)

VXFExILXXY (813-822)

KTXMVXQIES (912-921)

VVXKMXDVHFK (1078-1088)

VXPXTXPL (1169-1176)

AYPPKXRXA (1311-1319)
Figure 1. Determination of peptide sequences of DSD-1-PG. Amino acid sequences of 27 internal peptides obtained by trypsin and subtilisin treatment of the DSD-1-PG core protein are shown. The numbers in parentheses indicate the corresponding positions of the peptides in the deduced DSD-1-PG/mouse phosphacan sequence shown in Figure 2.

PCR amplification. This includes the entire $4.8 \mathrm{~kb}$ coding sequence and the corresponding 1612 amino acid sequence of the protein.

Overall, the mouse homolog has $90 \%$ identity (97\% similarity based on semi-conservative amino acid substitutions) with the rat sequence (Maurel et al., 1994). As illustrated in Figure 3, there is a predicted signal peptide in the first 24 residues, followed by a carbonic anhydrase-like domain from 34 to 302 and a fibronectin type III domain from 312 to 406, although the remainder of the protein has no apparent strong homology with other known proteins. The relationship of the mouse $\mathrm{RPTP} \beta / \zeta$ splice variants to the phosphacan sequence is also shown. Mouse phosphacan represents the entire extracellular portion of the long form of $\mathrm{RPTP} \beta / \zeta$ up to the transmembrane domain. The short form of $\mathrm{RPTP} \beta / \zeta$ represents a splicing variant, in which the 860 amino acid sequence from residue 756 to the transmembrane domain is deleted. Both forms of RPTP $\beta / \zeta$ possess the two intracellular tyrosine phosphatase domains, only the first of which seems to be active according to studies of the human protein (Krueger and Saito, 1992). Northern blots of P7 total brain mRNA using probes corresponding to the N-terminal half of mouse phosphacan confirm the presence of three mRNAs at $\sim 9.5,8.4$, and $6.5 \mathrm{~kb}$ (data not shown), corresponding to the long $\mathrm{RPTP} \beta / \zeta$, phosphacan, and the short RPTP $\beta / \zeta$, respectively (Maurel et al., 1994).

\section{Expression and glycosylation of DSD-1-PG}

As further evidence of the identity of DSD-1-PG as mouse phosphacan, the developmental expression profiles of the proteoglycans were compared, as was the cross-reactivity of various antibodies. In Western blots of mouse-brain extracts (Fig. 4), DSD-1-PG occurs as a very high molecular mass smear that has been estimated by gel filtration to be $\sim 800-1000 \mathrm{kDa}$ (Faissner et al., 1994). This is first detected around E13 and then shows a 
-105 CCTAGACCCTGGCCAGTCACCGGCGTCCCCTGCCTCGGTGTCCCCACCCTCTGTACCCTAAGCTGTACCCCTGCGGCTGGCGAGGGGCCGCGGACCGGGCTGGAG -1 ATGCGAATCCTGCAGAGCTTCCTCGCGTGCGTTCAGCTCCTGTGCCTGTGTCGCCTGGACTGGGCTTATGGATACTACAGACAACAGAGGAAACTTGTTGAAGAGATTGGCTGGTCCTAC 12

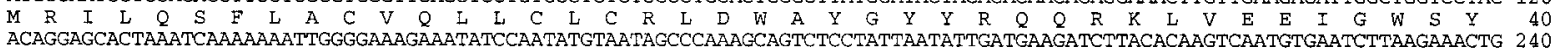
ACAGGAGCACTAAATCAAAAAATTGGGGAAGAAATATCCAATATGTAATAGCCCAAGCAGTCTCCTATTAATATTGATGAAGATCTTACACAAGTCAATGTGAATCTTAAGAAACTG 240
$\mathrm{~T} / \mathrm{G} / \mathrm{L} / \mathrm{N}$

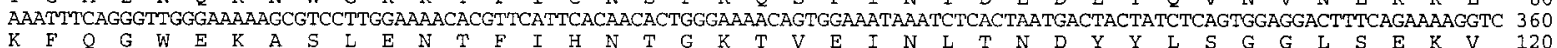

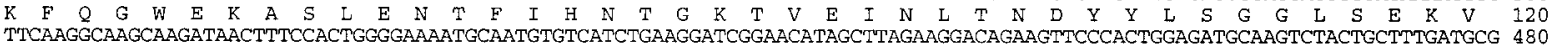
$\begin{array}{llllllllllllllllllllllllllllllll} & \end{array}$

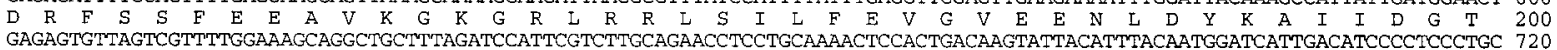

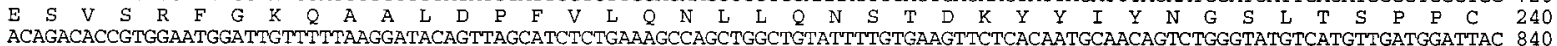

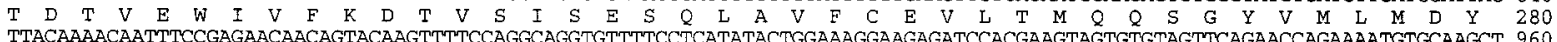

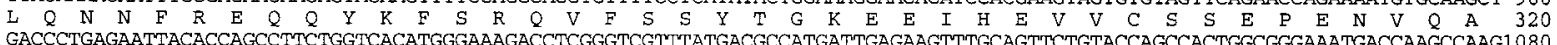
GACCCTGAGAATTACACCAGCCTTCTGGTCACATGGGAAAGACCTCGGGTCGTTTATGACGCCATGATTGAGAAGTTTGCAGTTCTGTACCAGCCACTGGCGGGAATGACCAAGCCAAG1080 CATGAGTTCTTAACAGATGGCTATCAGGACTTGGGTGCCATTCTCAATAATTTACTACCTAACATGAGTTACGTTCTTCAAATAGTGGCCGTATGCTCTAATGGTTTATATGGAAGTAC1200 $\begin{array}{lllllllllllllllllllllllllllllllllllllllllll}H & E & F & L & T & D & G & Y & Q & D & L & G & A & I & L & N & N & L & L & P & N & M & S & Y & V & L & Q & I & \text { V } & A & V & C & S & N & G & L & Y & G & K & Y & 400\end{array}$

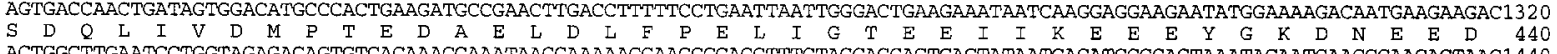
ACTGGCTTGAATCCTGGTAGAGACAGTGTCACAAACCAAATAAGGAAAAAGGAACCCCAGGTTTCTACCACGACTCACTATAATCACATGGGGACTAAATACAATGAAGCCAAGACTAAC1440 $\begin{array}{cccccccccccccccccccccccccc} & \end{array}$

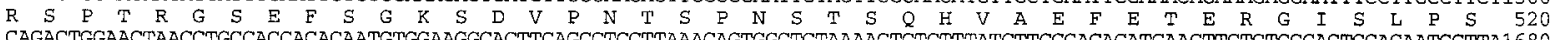
Q T G G T A L L AATACGGTTCCCATAACAGAGTACAAAGAGGTTCTGCTGACGTCAGTGAGGAAGAAACTTCCTGACTGATTTCAAGCTCGATACGGGAGCCGATGACTCTTCAGGCTCCAGCCCCTCA1800

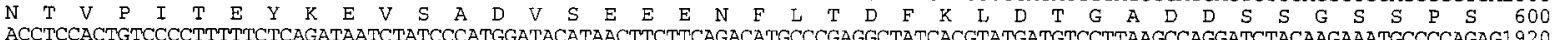

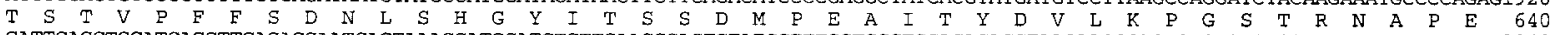
GATTCAGCTCCATCAGGTTCAGAGGAATCACTAAAGGATCCATCTCTTGAAGGGAGTGTATGGTTTCCTGGCTCCACAGACCTAACAACGCAGTCTGAGACTGGATCCGGCCGAGAGAGC20 40 TTTCICCAGGTTAACTCCACAGACATACAAATTIGATGAATCGAGGGAGACAACCGAGTCGTTTTCTCCAGATGCTACCGTGTCACAGGATCCTTCAGTCACAGACATGGGAATGCCACAT2160

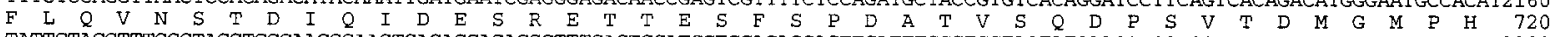

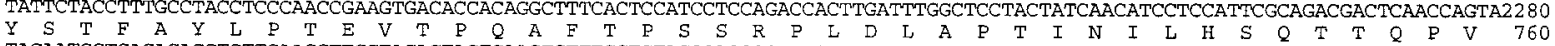
TACAATGGTGAGACACCTCTTCAACCTTCCTACAGTAGTGAAGTCTTTCCTCTAGCCACCCCTTTGTTGCTTGACAATCAGACCCTCAACACTACCCCTGCTGCTTCAAGTAGTGATTCG2400

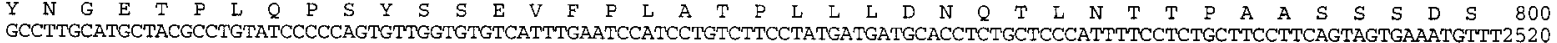

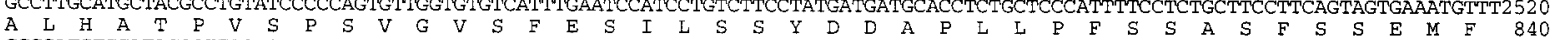
CGCCATCTGCATACGGTTTCTCAAACCCTTCCGCAAGTCACTTCAGCTGCTGAGAGGGATGAGCTGTCTTTGCATGCTTCTCTGCTGGTGGCTAGGGGTGATTGGCTGTTAGAACCAGC2640

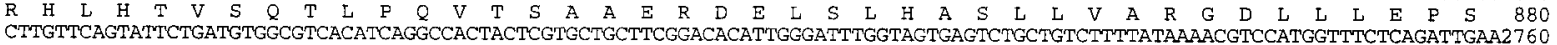

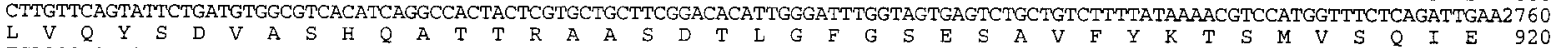
TCACCCAGAAGTGATGTTGTTATGCATGCATACTCTTCGGGGCCTGAACCTTCTTATACCGTTGAGGGCTCCCACCACGTACCCACTGTTTCTTACAGTTCTGCAATGCCTCTGCATGGT2880

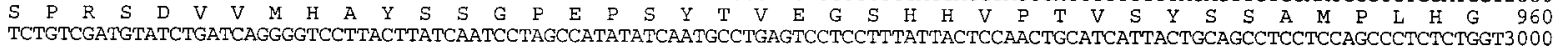

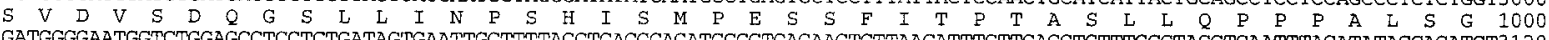

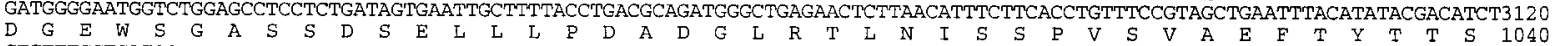
GTGTTTGCTGATGGTATTAAGCCGCTCTCTAAAAGTGAAATGATGTATGGAAATGAGACTGAACTGAAAATGTCTTCTTTCAGTGACATGGCATACCCTTCTAAAAGCACAGTTGTGCCA3240

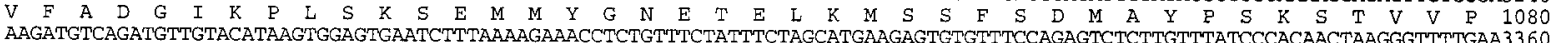
AAGATGTCAGATGTTGTACATAAGTGGAGTGAATCITTAAAAGAACCTCTGTPTCTATTTCTAGCATGAAGAGTGTGTTTCCAGAGTCTCTTGTTTATCCCACAACTAAGGGTTTTTGAA3360

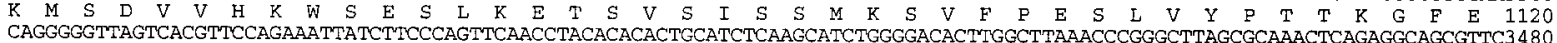
$\begin{array}{lllllllllllllllllllllllll} & \end{array}$ TCAGACACTGCTTCTAGGGAAGTAGTACACCCTTCAACACAGCCCTTGCTCTATGAGGCCGCAACTCCTTTTIAATACTGAAGCGTTGCTGCAACCTTCCTTTCAGGCTTCTGATGTTGAC3600

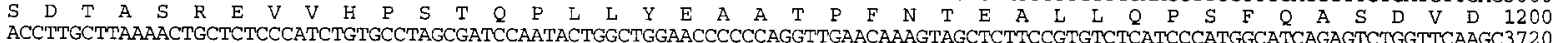

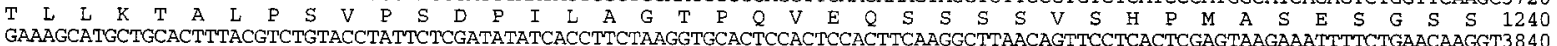

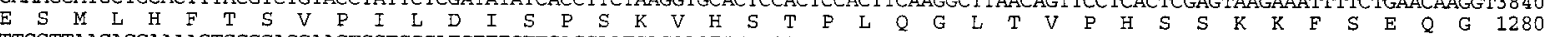
TTGCTTAAGAGCAAAAGTCCCCAGCAAGTGCTGCCATCTTTGTTCAGCAATGACGAGTTTPTTCCAAAACGCACATCTGGACGTTAGCCAGGCCTATCCTCCAAAAGGGAGGCATGCATTI3960 $\begin{array}{lllllllllllllllllllllllllllllllllllllllll}L & L & K & S & K & S & P & Q & Q & V & L & F & S & L & F & S & N & D & E & F & F & Q & N & A & H & L & D & V & S & Q & A & Y & P & P & K & G & R & H & A & F & 1320\end{array}$ $V$ T $P$ V CCAACGCTTGCTTCTGATGTACTTTCATCTACTGACCATTCTGTTCCATTAGGAGTGGGCCCATTCCTTGACAATGGTTTCTCCCAACAGAGATGATTCTGTGACCACAGCCAAGTT4200

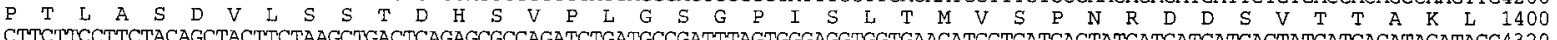

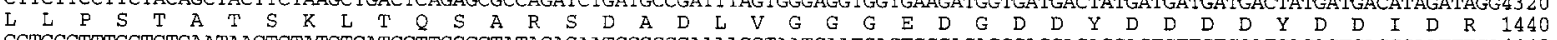
GGTCGCTTTCCTGTGAATAAGTGTATGTCATGCTTGCCCTATAGAGAATCCCGGGAAAAGGTAATGAATGACTCGGACACCCAGGAGAGCAGTCTTGTGGATCAGAGTGACCCAATTTCA44

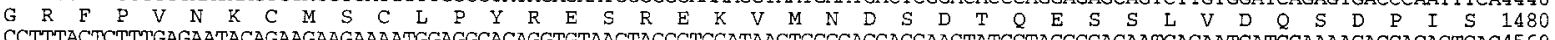

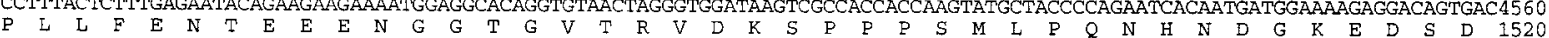
ATCCAAATGGGTAGTGCTGTCCTTCCTCATACCCCAGGATCTAAAGCGTGGGCAGTTTTGACAAGTGATGAAGAGAGTGGGTCAGGGCAAGGCACCTCAGATAGCCTTAATGATAATGAG4680

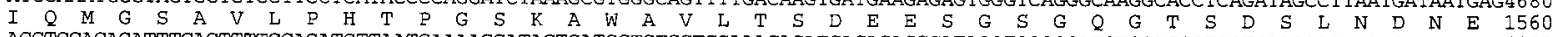
ACGTCCACAGATTTCAGTTTTCCAGATGTTAATTAAAAGGATACTGATGGTGTCCTSGAAACAGATGACACAGGCATAGCTCCGGGATCTCCACGGTCCTCCACACCATCTGTTACTAGT 4800 GGGCACTCAGGAGTATCCAACAGTTCAGAGGCAGGTTAGTTATGAGCAAAGGAAAGAATGAGATGTGATGATTTCTTGCTATGAAAGTAAAAAAATAGAAGAATCGTGGAAGAAAGGAA4920 $G \quad H \quad S \quad G \quad V \quad S \quad N \quad S \quad S$ E $A$ G *

TTCCGGTCCACCAGCAGACCTTCACTTTTTAACCAGAACGTTCAACCATTTGTAGCTCCTATAAATATAATTTCACTCATGATTTCAAATGAATATCCAACATATTTTTTGGTCCTTGGTT5040 TAATTATCTTCAAAATACATTGTTTGTGTGTTGTTACTAATTCCTATTCTACAGGATTCCTATTGGTGTGTACAATCAATTATATATGCATAATACACCGTTAGTATATTTGCAATGCAGTG5160 TGCTGTGTTAAGACAATTTAAATGTTCATACTTGTATTTCTAAAATAAGTTGTAAACCAATTCTATTGGATTTAAAATCTCAGTAATATGCTATGAGCACCTATCCACCAACAGAAACAAA5280 GGAGACACTTCCCATGTGCACATCAACGTGGAGAGCTTCTAAAAAAGAATTACAGGGCTATGATTTGATAGCTAAGGAAGGTTTTTGAAAAACATCATATTGCTTTTAAAACTATTCTTTCT5400 TTGAGCTTCTTTATGTTGCCTAAAGAGGGCAGTATAAACCAGCAAAATACATTCTACTTCGTGTTTGTTACAGTATTTGTCATTCCGGCTTAAATAAATAGACATGAATATGCATAGTAGT5520 TTGAGCTTCTTTATGTTGCCTAAAGAGGGCAGTATAAACCAGCAAAATACATPCTICTTCGTGTTTGTTACAGTATTTGTCATTCCGGCTTAAATAATAGACATGAATATGCATAGTAGT5520 ATAGGTATTGTGTGACAAGATGTAAAAAGAAGAAAGAAAAAAAAGAAAAAAGCCTAGAGCCTTTTCTGTAGGGATGCATTTCATTGTTAATATATTTTTATGCAAATTGGTTTTATTAGCC5640 AGATGTTTCTTGAAGCAGACTGCAACATGCAATACAGATGTGTGCTTTAAATGTCAATGGCAAAAAAACTCGAGTTTCATTCCATTIAAGTGTATAAAAAAAAAAGAGAGATGATTCCATTG5 760

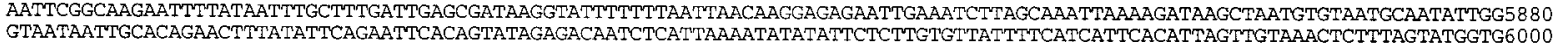
GTAATAATTGCACAGAACTTTATATTCAGAATTCACAGTATAGAGACAATCTCATTAAAATATATATTCTCTTGTGTTATTTTCATCATTCACATTAGTTGTAAACTCTTTAGTATGGGTG6000 GCAATTAAGAGATTATATATTTAGACAGGGCAGCTTCTTTTTTCTGTATTCTGGCTTGAACTCCATTTPAACGCTGCATTTCAGCTYCAAATGTCTGAACTGATGTGTGAGTGGGACTAATG6120 AGTCCACGGGTCACTGTAGTCAGGAGTGTTGTTACATATGTGAATTGTTTATCCATCCTCAATTATAGCACTTGGTTTTCTTTCTATATTTTTAGATTTATTTTGAAAGGGAAAGATGATGA6240 A'TATACTCTAATGGAGAGACCATACATATATAACAAAGCACTACATCTAGAATTATTGAAGAAAGTGATTTCTCTTAGATGTACTAATTAGATTPTTTTTTAACTGTTAAAGTTCCCCCAC6360 TAACGAAAAAAAGCAATATGGATATAACACCCATCTTCAGGAAATAATATAATTAATGAAGGAAGTAGGATCAAATAGAATTAGGGAAAACATTTTTTTACCTATTTTTAAAAAACTCTATC6480

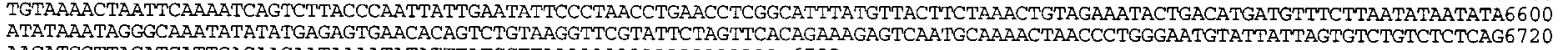
AACATGCTTACATGATTGAGAACAATAAAATATATTTATGCTTAAAAAAAAAAAAAAAAAAA 6782

Figure 2. Nucleotide sequence of DSD-1-PG/mouse phosphacan. The $6.8 \mathrm{~kb}$ nucleotide sequence of the DSD-1-PG/mouse phosphacan cDNA is shown together with the deduced 1612 amino acid sequence of the $4.8 \mathrm{~kb}$ open reading frame. +1 marks the start of the coding region; * indicates the stop codon at the end. The $3^{\prime}$ untranslated region ends in the poly(A) tail. The accession number for this sequence in the EMBL database is AJ133130. 
a)

DSD-1-PG/
PHOSPHACAN
1612 aa, $175 \mathrm{kD}$

RPTP $\beta / \zeta$
LONG
2312 aa, $255 \mathrm{kD}$

RPTP $\beta / \zeta$
SHORT
1464 aa, $165 \mathrm{kD}$

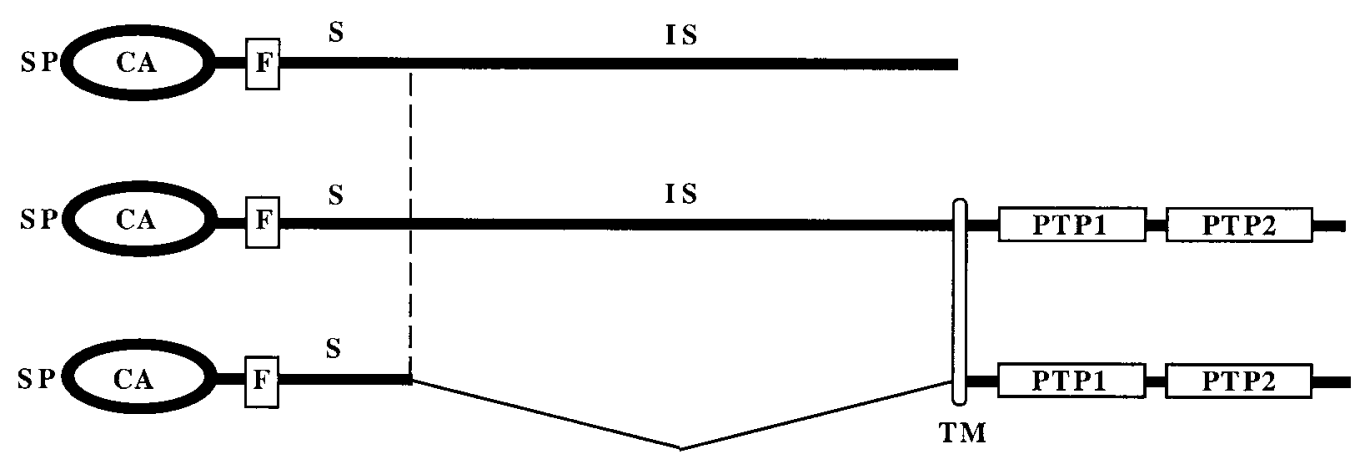

b)

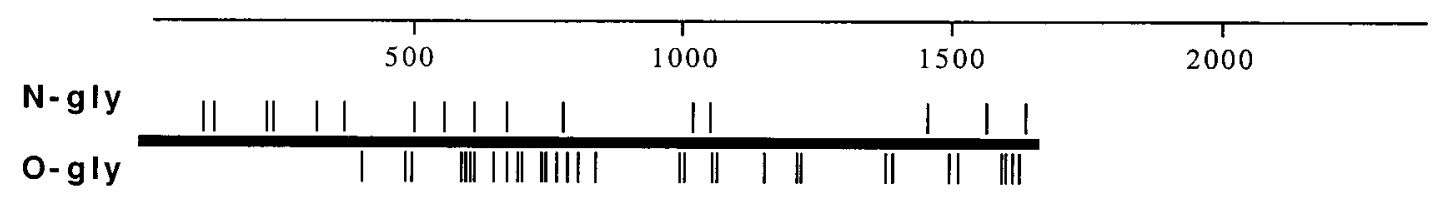

Figure 3. Structure of the DSD-1-PG/mouse phosphacan protein. $a$, Relationship of DSD-1-PG to RPTP $\beta / \zeta$ long and short forms. SP, Signal peptide; $C A$, carbonic anhydrase domain; $F$, fibronectin type III domain; $S$, remaining extracellular region of short RPTP $\beta / \zeta ; I S$, intervening sequence; TM, transmembrane domain; $T P$, tyrosine phosphatase domain. $b$, Predicted glycosylation sites of DSD-1-PG/mouse phosphacan: N-glycosylation ( $N$-gly) is shown above the line, and O-glycosylation $(O-g l y)$ below.

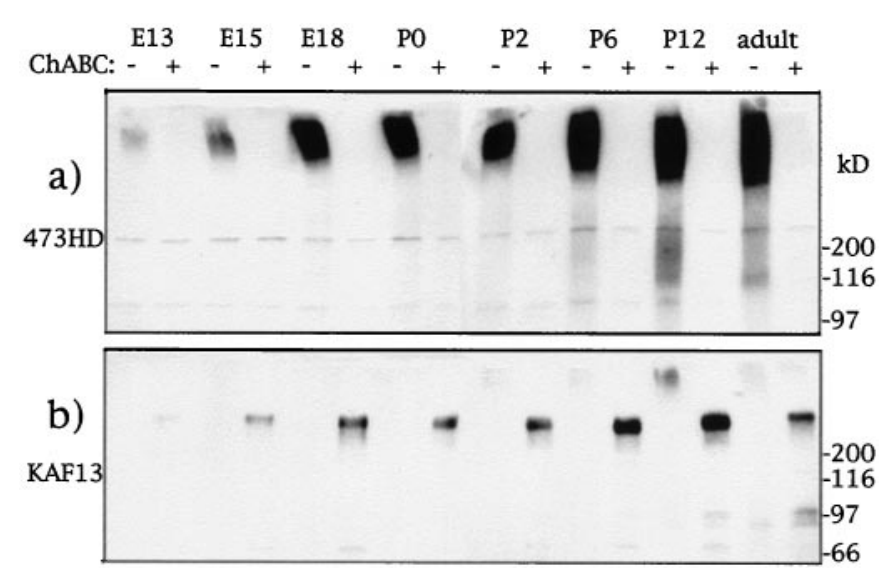

Figure 4. Developmental expression of DSD-1-PG in mouse brain lysates. Total protein $(100 \mu \mathrm{g})$ extracted from brains of the indicated ages (extraction buffer: $50 \mathrm{~mm}$ Tris, $\mathrm{pH} 8,50 \mathrm{~mm}$ sodium acetate, $60 \mathrm{~mm}$ $n$-octyl- $\beta$-D-glucopyranoside) were resolved on $4-10 \%$ SDS-PAGE gels and blotted onto polyvinylidene difluoride (PVDF) membrane. Extracts were either undigested $(-)$ or predigested $(+)$ with chondroitinase ABC $(C h A B C)$ as shown. Blot $a$ was developed with 473HD mAb, and blot $b$ was developed with the anti-DSD-1-PG polyclonal serum KAF13.

dramatic increase in expression to plateau around the second postnatal week, although it remains at high levels in the adult brain (Fig. 4a). When the CS GAGs of DSD-1-PG are digested by chondroitinase $\mathrm{ABC}$, the $\mathrm{CS}$ epitope recognized by $\mathrm{mAb} 473 \mathrm{HD}$ is also removed. The resulting core glycoprotein, which can be visualized with the pAb KAF13, has a relative molecular mass of $\sim 350-400 \mathrm{kDa}$ and shows the same developmental profile as the whole CSPG (Fig. $4 b$ ). This expression pattern is very similar to that given for rat phosphacan (Meyer-Puttlitz et al., 1995).

DSD-1-PG can be readily extracted from CNS tissues using mild buffers in the absence of detergent (Faissner et al., 1994). As the mouse homolog of phosphacan, and hence the secreted form of RPTP $\beta$, antibodies recognizing DSD-1-PG should also recognize the receptor isoforms. In membrane preparations extracted with $1 \% \mathrm{w} / \mathrm{v}$ NP40-containing buffers, it was indeed possible to visualize bands on Western blots corresponding to the transmembrane RPTP $\beta$ isoforms with 473HD and KAF13 (data not shown). The high molecular weight smear in the extracts could be digested with chondroitinase $\mathrm{ABC}$ to give core glycoproteins $\sim 400$ and $250 \mathrm{kDa}$ (the long and short RPTP $\beta$, respectively), similar to the pattern in rat tissue (Sakurai et al., 1996).

From the cDNA sequence, the predicted size of the core protein of DSD-1-PG/mouse phosphacan is $175 \mathrm{kDa}$. The discrepancy between the theoretical mass and the observed migration of the core protein after $\mathrm{ChABC}$ digestion is an indication of the degree of other carbohydrate modifications on the protein. There are 16 potential $\mathrm{N}$-glycosylation sites in both rat and mouse phosphacan [PROSITE; Bairoch et al. (1997)] and approximately 30 predicted O-glycosylation sites (Hansen et al., 1995) (Fig. 3b).

In rat phosphacan, a distinction has been made based on mutually exclusive carbohydrate epitopes recognized by the mAbs 3F8 and 3H1 (Rauch et al., 1991; Maurel et al., 1994). The 3F8 N-linked oligosaccharide epitope is present on phosphacan, whereas $3 \mathrm{H} 1$ reacts with a keratan sulfate epitope present on a keratan sulfate glycoform of phosphacan, termed phosphacan-KS (Maurel et al., 1994). As can be seen in Figure 5, the purified DSD-1-PG is recognized by both $3 \mathrm{H} 1$ and $3 \mathrm{~F} 8$, indicating the presence of both epitopes, and the $3 \mathrm{H} 1$ reactivity on DSD-1-PG can be digested by keratanase. Because DSD-1-PG is purified by affinity chromatography with the $473 \mathrm{HD} \mathrm{mAb}$, the implication is that the DSD-1 epitope is present, at least in mouse, on both the phosphacan and phosphacan-KS glycoforms. A protein epitope in the N-terminal half of rat phosphacan recognized by another mAb, 2B49 (Sakurai et al., 1996), is apparently absent from DSD-1-PG (data not shown).

Two other characterized carbohydrate epitopes recognized by mAbs L2 and L5 have also been found on DSD-1-PG (Fig. 6). L2 


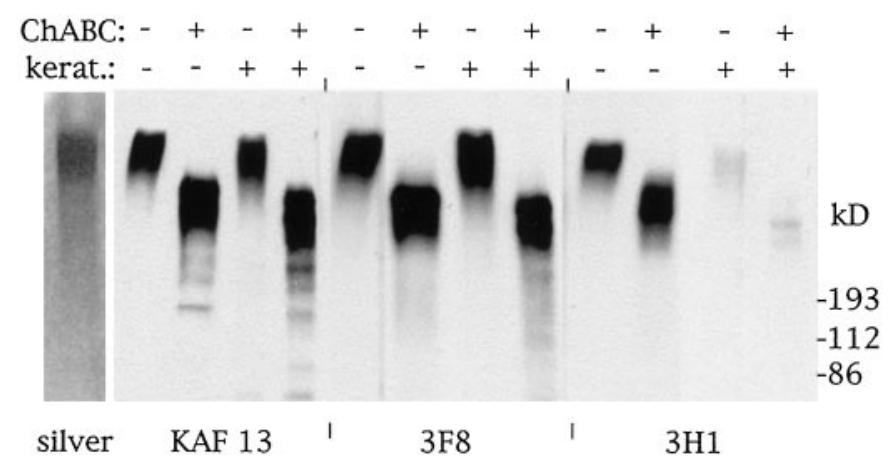

Figure 5. Western blot studies of purified DSD-1-PG. First lane shows silver staining of $3 \mu \mathrm{g}$ of purified DSD-1-PG migrated on a $4-10 \%$ SDS-PAGE gradient gel. Other lanes show purified DSD-1-PG $(0.7 \mu \mathrm{g})$ digested with chondroitinase $\mathrm{ABC}(\mathrm{Ch} A B C)$ or keratanase as indicated, before resolution on a $4-10 \%$ SDS-PAGE gradient gel and blotting onto PVDF membrane. Transferred protein was developed with KAF13, 3F8, and $3 \mathrm{H} 1$ antibodies.

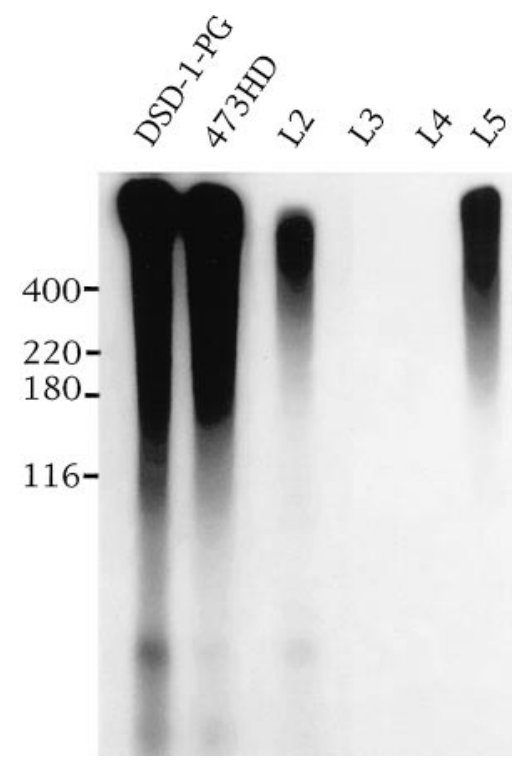

Figure 6. Immunoprecipitation of $\mathrm{I}^{125}$-labeled DSD-1-PG with monoclonal antibodies. I ${ }^{125}$-labeled DSD-1-PG $\left(10^{6} \mathrm{cpm} /\right.$ precipitation $)$ was incubated with monoclonal antibodies $473 \mathrm{HD}, \mathrm{L} 2 / \mathrm{HNK}-1, \mathrm{~L} 3, \mathrm{~L} 4$, and L5 as indicated, and immunoprecipitates were resolved on a $4-10 \%$ SDS-PAGE gradient gel. The first lane contains I ${ }^{125}$-labeled DSD-1-PG $\left(5 \times 10^{4} \mathrm{cpm}\right)$. An autoradiograph of the gel is shown.

recognizes the HNK-1 epitope, a sulfated glucoronic acid carbohydrate found on several neural recognition molecules, such as L1 and N-CAM (Kruse et al., 1985), which has been shown to be involved in the migration of neural crest cells in vivo (BronnerFraser, 1987) and has been implicated in vitro in neuronal migration, neurite outgrowth (Lallier and Bronner-Fraser, 1991; Lallier et al., 1992), and short-term cell-to-cell and cell-to-laminin adhesion (Keilhauer et al., 1985; Kunemund et al., 1988; Hall et al., 1993). It was not possible to remove the L2/HNK-1 epitope from DSD-1-PG using peptide-N-glycosidase F, keratanase, or ChABC (data not shown), an observation similar to that found with rat phosphacan (Rauch et al., 1991; Maeda et al., 1995).

The L5 mAb has been shown to recognize the Lewis-X N-linked carbohydrate structure (Streit et al., 1996), which appears to play a role in early neurogenesis (Roberts et al., 1991) and astrocytic process formation (Streit et al., 1993). Lewis-X, as recognized by the mAb FORSE-1, has also been found on rat phosphacan (Allendorfer et al., 1995). The L5 antibody has also been used to characterize astrochondrin, a large mouse CSPG expressed by mature astrocytes (Streit et al., 1990, 1993). On digestion of its CS GAGs, astrochondrin migrates as three core proteins at $\sim 380,360$, and $260 \mathrm{kDa}$. It also carries the L2/HNK-1 epitope and the DSD-1 epitope (Streit et al., 1993) and has been described as the only L5-bearing CSPG expressed by astrocytes, showing a developmental profile similar to DSD-1-PG (Streit et al., 1990, 1993), which is also expressed by GFAP+ astrocytes (Schnädelbach et al., 1998). As such, it is possible that there is some identity between DSD-1-PG and astrochondrin.

Other CSPGs have been described whose core proteins show a relative migration similar to DSD-1-PG on SDS-PAGE, but in the absence of peptide sequences or antibody cross-reactivity further identification would be hazardous.

The epitope recognized by mAb 6B4 has been found on migrating neurons (Maeda et al., 1995), and in situ hybridization analysis of sections from the developing brain indicate that there are subsets of neurons that express RPTP $\beta$ and phosphacan (Snyder et al., 1996). In the case of DSD-1-PG, colocalization of several antibody markers on cerebellar cultures in vitro does not show an overlap of L1 as a neuronal marker with DSD-1 (Faissner et al., 1994; Schnädelbach et al., 1998), nor in various immunohistochemical studies has a staining of neurons been evident (Gates et al., 1995; Heyman et al., 1995; Steindler et al., 1995; Wintergerst et al., 1996), although this may reflect higher levels of DSD-1-PG expression and secretion by glial cells compared with neurons. Perhaps in situ hybridization studies using appropriate cDNA probes will prove more sensitive in this respect.

\section{DSD-1-PG/mouse phosphacan promotes neurite outgrowth from hippocampal neurons grown on PORN but inhibits neurite outgrowth from DRG explants grown on laminin}

The identification of DSD-1-PG as the mouse equivalent of rat phosphacan presents some contradictions concerning the functional activity of the proteoglycan in neurite outgrowth assays. Although DSD-1-PG has clear outgrowth-promoting properties when tested on rat E14 mesencephalic and E18 hippocampal neurons (Faissner et al., 1994) and phosphacan has been reported to promote morphological differentiation of E16 rat cortical neurons grown at low density on poly-L-lysine (Maeda et al., 1995; Maeda and Noda, 1996), phosphacan has also been shown to inhibit neurite outgrowth from E9 chicken brain neurons plated on NgCAM (Grumet et al., 1993; Milev et al., 1994).

To test the possibility that DSD-1-PG may also be capable of inhibiting neurite outgrowth under other conditions, a comparison was made of the effects of DSD-1-PG on neurons from DRG explants and on hippocampal neurons. As reported previously, DSD-1-PG promotes neurite outgrowth from hippocampal neurons when plated as a substrate on PORN (Faissner et al., 1994). When plated under the same conditions, however, DRG explants displayed no change in neurite outgrowth on DSD-1-PG relative to PORN alone (Table 1, Fig. 7). Because PORN may be considered to be the equivalent of a minimal substrate for the neurons, the apparent absence of an effect of DSD-1-PG on the DRG explants might mask a negative effect. To test for possible inhibitory effects, the neurons were plated on laminin, chosen as a good supportive substrate for neurite outgrowth (Lander et al., 1985; Luckenbill-Edds, 1997), which has been used previously as a plating substrate in several studies of the inhibitory effects of CS 
Table 1. Summary of neurite outgrowth assays comparing the effect of DSD-1-PG coated on PORN or laminin on hippocampal neurons and DRG explants

\begin{tabular}{|c|c|c|c|c|c|c|}
\hline \multirow[b]{2}{*}{ Substrate } & \multicolumn{3}{|c|}{ E18 Hippocampal neurons } & \multicolumn{3}{|c|}{ P0/P1 DRG explants } \\
\hline & $\begin{array}{l}\text { Total no. of } \\
\text { analyzed } \\
\text { neurons }\end{array}$ & $\begin{array}{l}\text { Neurite-bearing } \\
\text { cells }(\%) \pm \mathrm{SE}\end{array}$ & $\begin{array}{l}\text { Mean neurite } \\
\text { length }(\mu \mathrm{M}) \\
\pm \mathrm{SE}\end{array}$ & $\begin{array}{l}\text { Total no. of } \\
\text { analyzed } \\
\text { explants }\end{array}$ & $\begin{array}{l}\text { Neurite-bearing } \\
\text { cells }(\%) \pm \mathrm{SE}\end{array}$ & $\begin{array}{l}\text { Mean neurite } \\
\text { halo }\left(\mathrm{mm}^{2}\right) \\
\pm \mathrm{SE}\end{array}$ \\
\hline PORN & 300 & $40.3 \pm 3$ & $26.4 \pm 1$ & 20 & $30.0 \pm 1$ & $1.5 \pm 0.3^{a}$ \\
\hline PORN + DSD-1-PG & 300 & $62.3 \pm 4$ & $39.7 \pm 2$ & 35 & $28.6 \pm 1$ & $1.6 \pm 0.2^{a}$ \\
\hline $\mathrm{LN}$ & 300 & $79.0 \pm 4$ & $59.0 \pm 2$ & 43 & $65.1 \pm 4$ & $4.5 \pm 0.5$ \\
\hline $\mathrm{LN}+\mathrm{DSD}-1-\mathrm{PG}$ & 300 & $87.0 \pm 3$ & $50.8 \pm 2$ & 44 & $31.8 \pm 3$ & $2.8 \pm 0.3$ \\
\hline $\mathrm{LN}+$ DSD-1-PG/ChABC & 300 & $86.0 \pm 2$ & $51.4 \pm 1$ & 40 & $35.0 \pm 1$ & $3.2 \pm 0.5^{a}$ \\
\hline
\end{tabular}

Total number of analyzed neurons/DRG explants out of three independent experiments. SE, Standard error $(t$ test). LN, Laminin.

${ }^{a}$ Data from two experiments.

and CSPGs on DRG explants (Dou and Levine, 1994, 1995; Smith-Thomas et al., 1994; Katoh-Semba et al., 1995; Snow et al., 1996).

As can be seen in Table 1, plating the hippocampal neurons and DRG explants on laminin results in a doubling of both the percentage of neurite-bearing neurons and the mean length of these processes compared with the PORN substrate alone. The neurons on the DSD-1-PG/laminin substrate again responded differently (Table 1; Figs. 8, 9). Although there was no significant change in the outgrowth from the hippocampal neurons, the addition of DSD-1-PG to the laminin substrate resulted in a very striking reduction in both the percentage of neurite-bearing explants and the process lengths for the DRG explants. Thus, it appears that DSD-1-PG can indeed also inhibit neurite outgrowth but that these effects are dependent on the neuron cell type.

The inhibitory effects of CSPGs in some other assay systems have been attributed to the CS GAGs rather than the whole proteoglycan or the core protein (Fernaud-Espinosa et al., 1994; Smith-Thomas et al., 1994; Dou and Levine, 1995). In the case of DSD-1-PG, on the contrary, it is the outgrowth-promoting activity on hippocampal neurons that has previously been shown to be dependent on the CS GAG chains (Faissner et al., 1994; Clement et al., 1998). Indeed, in addition to being removed by ChABC digestion, this is an activity that can be specifically neutralized by the $\mathrm{mAb} 473 \mathrm{HD}$, implying that the DSD-1 epitope plays a direct role (Faissner et al., 1994). Here, however, removal of the CS GAGs by ChABC digestion of the DSD-1-PG substrate before plating of the neurons had no significant effect on either of the neuronal types studied, there being no alleviation of the inhibition observed with the DRG explants (Table 1). As such, it appears that the observed inhibition of the DRG outgrowth in this assay is associated with the core glycoprotein of DSD-1-PG rather than the CS GAGs.

\section{DISCUSSION}

We report here the identification of the core protein of DSD$1-\mathrm{PG}$ as the mouse homolog of phosphacan. In vitro studies have demonstrated that, under the same culture conditions, the purified DSD-1-PG can promote neurite outgrowth from one neuronal type and inhibit it from another.

\section{Neurite outgrowth and CSPGs}

CSPGs are generally regarded as barriers for neurite outgrowth (Snow et al., 1990a,b; Oohira et al., 1991; Dou and Levine, 1994; Milev et al., 1994). They have been shown to be associated with glial boundaries in the development of many CNS structures, including the roof plate and midline dorsal tectum, posterior sclerotome, dorsal root entry zone, and dorsal columns in the spinal cord, locations that are considered to be axon inhibitory regions (Fitch and Silver, 1997). In vitro studies show that CSPGs can inhibit neurite outgrowth and elongation (Snow et al., 1990a; Fichard et al., 1991; Oohira et al., 1991; Brittis et al., 1992; Dou and Levine, 1994; Maeda and Noda, 1996), effects that can be associated with either the whole PG, the CS GAGs (Snow et al., 1990a; Schwab et al., 1993), or the protein cores (Oohira et al., 1991; Grumet et al., 1993).

It is now clear, however, that there are also regions in which CS is found, such as the neocortex and retinal neurons (Bicknese et al., 1994; McAdams and McLoon; 1995, Ring et al., 1995), in which CSPGs cannot be regarded as a barrier to axonal outgrowth. Likewise, some in vitro studies indicate that brain CSPGs and/or CS GAG chains can promote neurite outgrowth (Iijima et al., 1991; Lafont et al., 1992; Faissner et al., 1994; FernaudEspinosa et al., 1994; Maeda and Noda, 1996).

\section{Neurite outgrowth and DSD-1-PG/mouse phosphacan}

There has been some confusion about the effects of phosphacan on neurite outgrowth. It has been shown to inhibit neurite growth from E9 chicken brain neurons plated on NgCAM (Grumet et al., 1993; Milev et al., 1994) but to promote morphological differentiation of E16 rat cortical neurons grown at low density on poly-L-lysine (Maeda et al., 1995; Maeda and Noda, 1996). The study with phosphacan plated on poly-L-lysine (Maeda and Noda, 1996) showed that the percentage of neurite-bearing cells was higher for both E16 cortical and E16 thalamic neurons but that although the length of the resulting neurites from cortical neurons was increased relative to poly-L-lysine, there was no corresponding change in the thalamic neurons.

Although these studies were with relatively crude mixtures of many different neuronal subtypes, they are not inconsistent with our contrasting observations of, on the one hand, a cell typespecific neurite outgrowth promoting activity of DSD-1-PG/ mouse phosphacan from hippocampal and mesencephalic neurons plated on PORN, yet on the other hand, a striking inhibition by DSD-1-PG of neurite outgrowth from DRG explants plated on laminin.

The inhibitory effects of DSD-1-PG are not removed by $\mathrm{ChABC}$ digestion, indicating that they are associated with the core glycoprotein. Interestingly, digestion of the CS GAG chains did not affect either the inhibitory or the promotory effects of phosphacan (Milev et al., 1994; Maeda and Noda, 1996), and although we have also found that the digestion of the CS GAG chains does not alleviate the inhibitory effects of DSD-1-PG on 


\section{A. Neurite bearing}

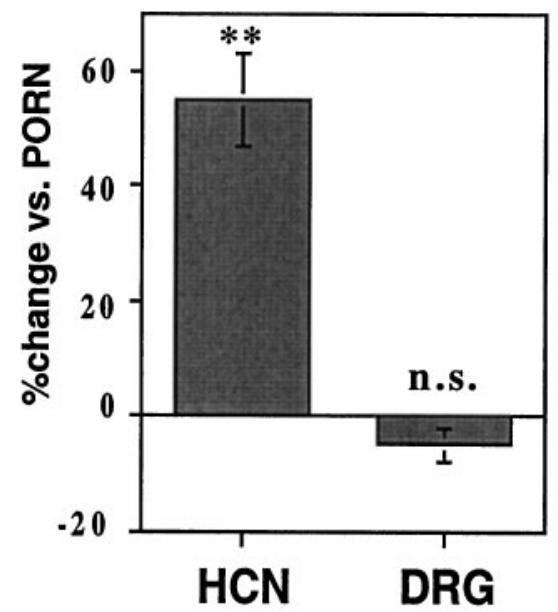

B. Neurite length

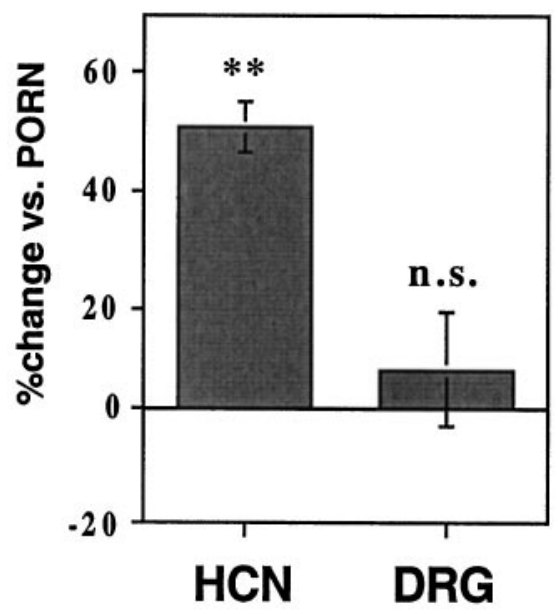

Figure 7. Neurite outgrowth response to DSD-1-PG/mouse phosphacan in the presence of PORN depends on neuronal lineage. Shown is a summary of neurite outgrowth assays comparing the effect of DSD-1-PG coated on PORN on hippocampal neurons $(H C N)$ and dorsal root ganglion explants $(D R G) . A$, The percentage change in neurite-bearing cells/explants versus the PORN control; $B$, the percentage of neurite outgrowth versus PORN. In the case of hippocampal neurons the length of the longest neurites was measured, whereas for the DRG explants, the surface area of the halo in square millimeters was measured. At least three independent experiments were analyzed, and the mean values of the neurite lengths/halos and percentage of neurite-bearing cells/explants were compared by $t$ test. $n$.s., Nonsignificant; ** $0.01>p>0.001$. Error bars represent the SE.

DRG explants, the neurite outgrowth-promoting effect of DSD1-PG on hippocampal neurons is mediated by the particular CS GAG structure DSD-1 (Faissner et al., 1994). This was shown by neutralization of outgrowth with mAb 473HD, and DSD-1enriched sulfated CS C and CS D preparations have now also been shown to promote the morphological differentiation of these CNS neurons (Clement et al., 1998).

Bacterially and eukaryotically expressed protein domain constructs corresponding to different parts of the core protein of phosphacan/RPTP $\beta / \zeta$ have been tested in neurite outgrowth

\section{A. Neurite bearing}

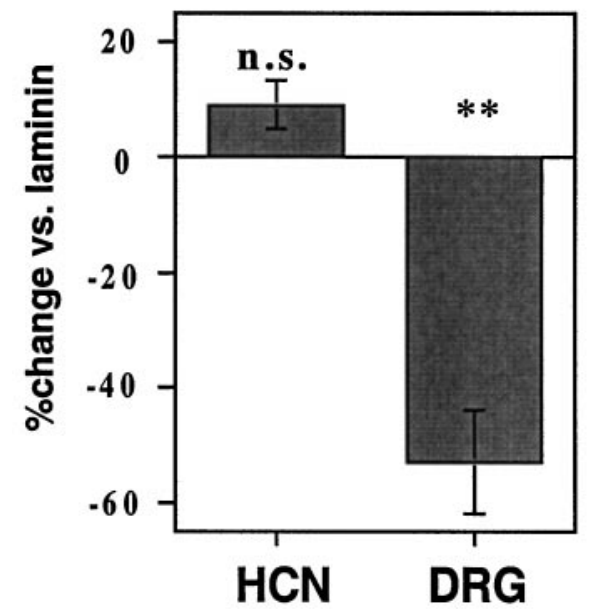

B. Neurite length

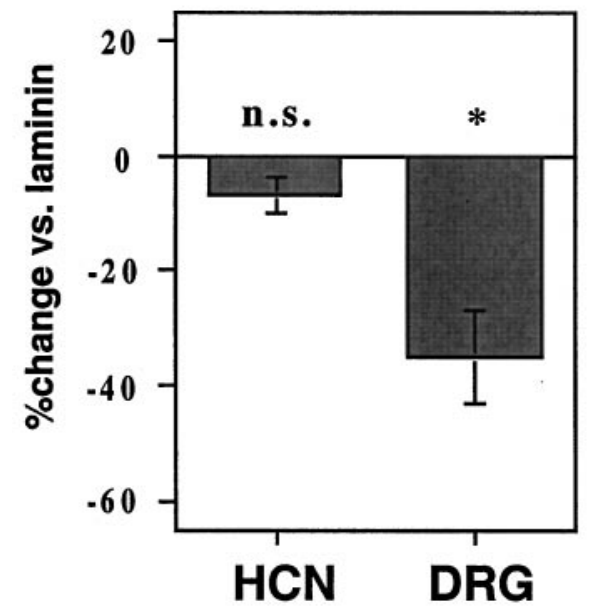

Figure 8. Neurite outgrowth response to DSD-1-PG/mouse phosphacan in the presence of laminin depends on neuronal lineage. Summary of neurite outgrowth assays comparing the effect of DSD-1-PG coated on laminin on hippocampal neurons $(H C N)$ and dorsal root ganglion explants $(D R G)$. $A$, The percentage inhibition/stimulation versus the laminin control; $B$, the percentage of neurite outgrowth versus laminin. At least three independent experiments were analyzed, and the mean values of the neurite lengths/halos and percentage of neurite-bearing cells/ explants were compared by $t$ test. $n$.s. Nonsignificant; ${ }^{*} 0.05>p>0.01$; $* * 0.01>p>0.001$. Error bars represent the SE.

assays (Peles et al., 1995, 1997; Sakurai et al., 1997). These indicated that outgrowth from chick tectal neurons could be supported by the carbonic anhydrase domain, an effect potentiated by addition of the "S" domain (Fig. 3).

In addition to the CS GAGs, DSD-1-PG is highly glycosylated with other carbohydrate modifications, as illustrated by the presence of the 3H1, 3F8, L2/HNK-1, and L5/Lewis-X epitopes. It appears likely that the sulfation, carbohydrate composition, and oligosaccharide structure of DSD-1-PG/phosphacan is developmentally regulated and that at least some of these carbohydrate modifications could alter its affinity for other proteins, for example, the N-linked sugars on the carbonic anhydrase and FN III 


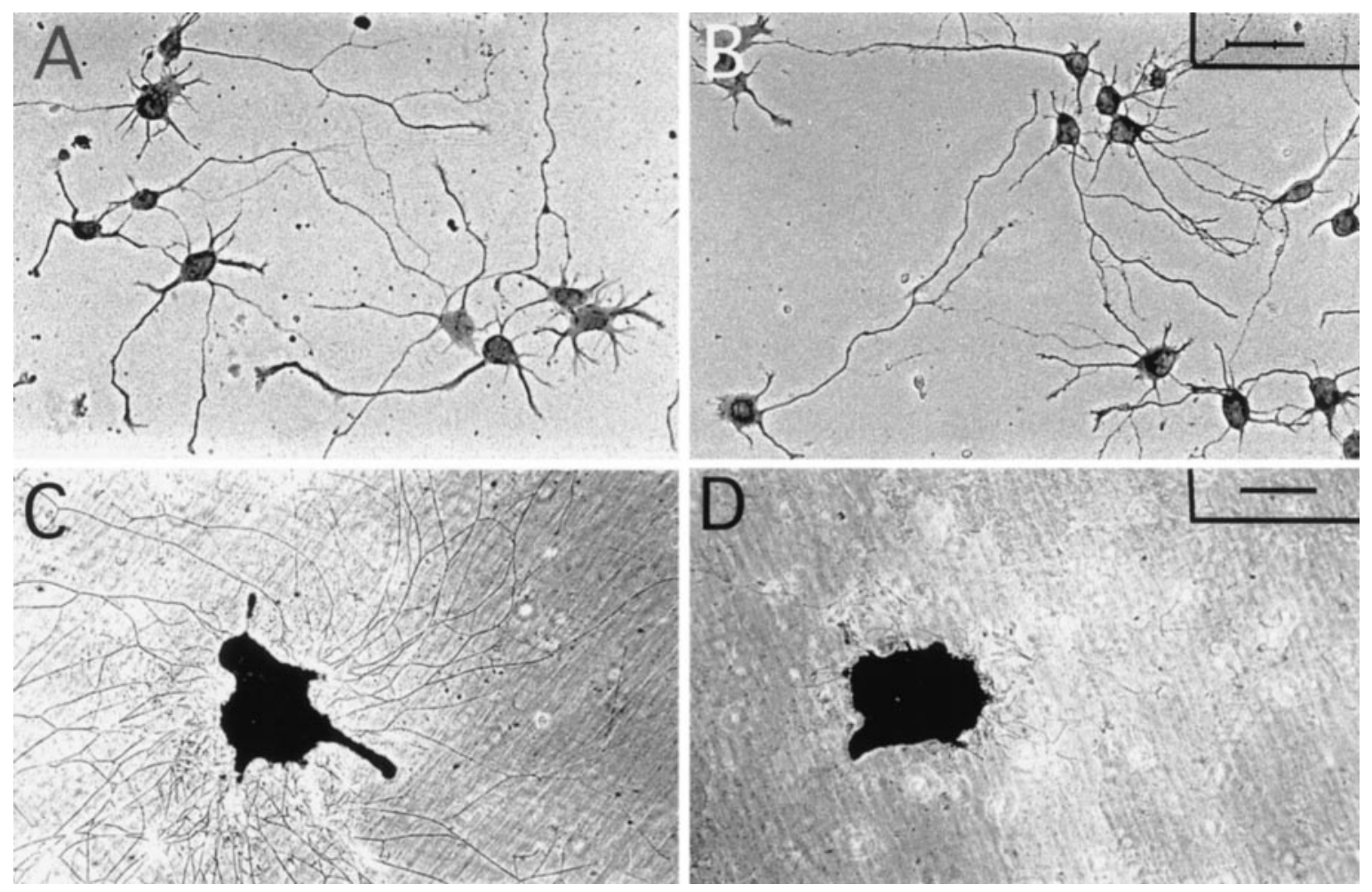

Figure 9. Neurite outgrowth assay of hippocampal neurons and DRG explants grown on laminin and DSD-1-PG/laminin. Hippocampal neurons and dorsal root ganglion explants were cultivated on laminin $(A, C)$ or laminin + DSD-1-PG $(B, D)$ for 1 and 3 d, respectively. Hippocampal neurons are shown by phase contrast, and the DRG explants were stained with toluidine blue. Scale bars: $A, B, 20 \mu \mathrm{m} ; C, D, 300 \mu \mathrm{m}$.

domains of phosphacan that mediate its interactions with NgCAM, NCAM, and Tenascin-C (Milev et al., 1995).

In effect, DSD-1-PG/phosphacan has been shown to possess three levels at which it can interact with other molecules either in the ECM or on cell membranes. These are the GAG chains, the other $\mathrm{N}$ - and O-linked oligosaccharides, and finally the regions of the protein core that are not covered by carbohydrate modifications. With such a range of possible interactions, it is not surprising that DSD-1-PG/phosphacan is implicated in many developmental processes such as migration and neurite outgrowth. In addition to variations in the presentation of such sites of interaction on the PG, the amplitude of its effects is likely to be dependent on localized combinatory variations, both quantitative and qualitative, of promoting and inhibitory factors that recognize these sites. Cell type-specific differences in the cell surface receptors when confronted with various potential ligands in the ECM, and the relative responsiveness of their intracellular signaling mechanisms to such factors, could then account for the differential cellular behavior observed.

\section{In vivo distribution of DSD-1-PG/mouse phosphacan}

The expression profile of DSD-1-PG matches that reported for rat phosphacan, with a rapid increase in its concentration during the late embryonic and early postnatal period, the levels remaining high in adult brain (Meyer-Puttlitz et al., 1995).

The distribution of DSD-1-PG during development has been found to correspond to regions related to the formation of axonal trajectories. In this respect, it might play either a neuritepromoting role, as in the interrhomberic boundaries in chick (Heyman et al., 1995), or an inhibitory role, which would correspond to its presence in glial barrel field boundaries in the developing somatosensory cortex of mouse (Steindler et al., 1995).

Studies of the distribution of both the phosphacan mRNA (Engel et al., 1996) and the expressed protein (Meyer-Puttlitz et al., 1996) show that at E13-16, for example, the phosphacan mRNA is largely confined to areas of active cell proliferation such as the ventricular zone of the brain and the ependymal layer surrounding the central canal of the spinal cord. Also, although the mRNA is mostly in the neuroepithelium of the embryonic brain and spinal cord, the protein is widely distributed in these tissues, presumably as a consequence of transport in or along glial processes, local secretion, and/or redistribution as a consequence of cell migration (Engel et al., 1996; Meyer-Puttlitz et al., 1996). Based on the punctual expression pattern of phosphacan throughout the developing nervous system, it has been proposed that it may play a role in neuronal migration, differentiation, and circuit formation (Maeda and Noda, 1996; Meyer-Puttlitz et al., 1996).

Studies of DSD-1-PG localization in mouse brain match those for phosphacan in rat. For example, at E17 it is expressed in the dorsal, dorsolateral, and lateral subventricular zones and the cortical subplate (Gates et al., 1995); in the P7 cerebellum, it is strongly expressed in all layers, except the external granule layer, where it is only found on the Bergmann glia fibers (our unpublished observations) (Rauch et al., 1991). Preliminary studies of P6 cerebellar neurons plated on PORN and DSD-1-PG also suggest a neurite outgrowth promotion by the PG (our unpublished observations).

The effects on neurite outgrowth observed with hippocampal neurons and DRG explants in culture can also be correlated with the in vivo expression of DSD-1-PG/phosphacan. In E19 rat brain, 
the strongest expression of phosphacan is in the marginal zone, subplate, and hippocampus (Meyer-Puttlitz et al., 1996). Furthermore, the DSD-1-epitope has been detected in the dentate gyrus of the rat hippocampus (Deller et al., 1997).

In the developing spinal cord, phosphacan is present in the growth territories of DRG axons. It is widely and strongly expressed by E13, being present in the dorsal root ganglion, the dorsal root entry zone, and the ventral roots, throughout the gray and white matter, and in the dorsal and ventral nerve roots present in the roof plate but not the floor plate (Meyer-Puttlitz et al., 1996). This pattern at E13 continues at E16 and E19 with more phosphacan in the dorsal, lateral, and ventral funiculi, in the motor columns, and the dorsal horn gray matter. On the basis of this distribution pattern, it has been suggested that phosphacan may be the PG that is associated with the inhibitory glial barriers to axonal extension at the dorsal root entry zones and in the roof plate of the spinal cord and that it may play a specific role in axonal growth and movement in the spinal cord by being in these glial-bordered extracellular spaces (Meyer-Puttlitz et al., 1996; Golding et al., 1997).

Similarly, several studies have reported the enhanced expression of growth-inhibiting CSPGs in the context of CNS lesions (McKeon et al., 1991; Bovolenta et al., 1993; Pindzola et al., 1993; Lips et al., 1995), and DSD-1-PG has also been found to be strongly upregulated after wounding in the CNS (Laywell et al., 1990; Laywell and Steindler, 1991; Barker et al., 1996; Deller et al., 1997), as has phosphacan (Snyder et al., 1996).

A study of the role of CSPGs in the outgrowth and adhesion of thalamic neurons plated onto living slices of the mouse embryonic neocortex (Emmerling and Lander, 1996) demonstrated that CS digestion could affect both the permissive environment of the subcortical plate and the neurite-repellent properties of the cortical plate. However, they suggest that the opposing activities of these different zones is attributable to differentially localized CS-binding factors rather than association with the presence of different CSPGs. As we show here, however, neurons from different regions of the CNS do not necessarily respond in the same way to the same CSPG. Hence, localized variations in the composition of the ECM may not always be required to obtain cell type-specific responses.

In the adult rat brain, it has been shown that DSD-1-PG occurs in perineuronal nets around parvalbumin-immunoreactive interneurons of the cerebral cortex because it was detected in the circumference of a selected subpopulation of neurons that expressed the calcium-binding protein parvalbumin occupying the extracellular space in close vicinity to the cell body and surrounding axon terminals and glial end feet but not the synaptic clefts (Wintergerst et al., 1996). It has been suggested that CSPGs associate with hyaluronic acid in such perineuronal nets or pericellular matrices to form a neuronal ECM structure analogous to that found in connective tissue (Maleski and Hockfield, 1997; Rauch, 1997). Different neuronal subsets have different complements of CSPGs (Celio and Blumcke, 1994) such that perineuronal CSPGs could regulate the extracellular milieu of neurons in cell type-specific ways. For example, late in development, the mature ECM may be an important element in limiting synaptic plasticity (Hockfield et al., 1990).

\section{REFERENCES}

Allendoerfer KL, Magnani JL, Patterson PH (1995) FORSE-1, an antibody that labels regionally restricted subpopulations of progenitor cells in the embryonic central nervous system, recognizes the Le(x) carbo- hydrate on a proteoglycan and two glycolipid antigens. Mol Cell Neurosci 6:381-395.

Bairoch A, Bucher P, Hoffman K (1997) The PROSITE database: its status in 1997. Nucleic Acids Res 25:217-221.

Banker GA, Cowan WM (1977) Rat hippocampal neurons in dispersed cell culture. Brain Res 126:397-425.

Barker RA, Dunnett SB, Faissner A, Fawcett JW (1996) The time course of loss of dopaminergic neurons and the gliotic reaction surrounding grafts of embryonic mesencephalon to the striatum. Exp Neurol 141:79-93.

Barthels D, Vopper G, Wille W (1988) NCAM-180, the large isoform of the neural cell adhesion molecule of the mouse, is encoded by an alternatively spliced transcript. Nucleic Acids Res 16:4217-4225.

Bicknese AR, Sheppard AM, O'Leary DM, Pearlman AL (1994) Thalamocortical axons extend along a chondroitin sulfate proteoglycan-enriched pathway coincident with the neocortical subplate and distinct from the efferent path. J Neurosci 14:3500-3510.

Blumenkrantz N, Asboe-Hansen G (1973) New method for quantitative determination of uronic acids. Anal Biochem 54:484-489.

Bovolenta P, Wandosell F, Nieto-Sampedro M (1993) Neurite outgrowth inhibitors associated with glial cells and glial cell lines. NeuroReport 5:345-348.

Brittis PA, Canning DR, Silver J (1992) Chondroitin sulfate as a regulator of neuronal patterning in the retina. Science 255:733-736.

Bronner-Fraser M (1987) Perturbation of cranial neural crest migration by HNK-1 antibody. Dev Biol 123:321-331.

Celio MR, Blumcke I (1994) Perineuronal nets: a specialized form of extracellular matrix in the adult nervous system. Brain Res Rev 19:128-145.

Clement AM, Nadanaka S, Masayama K, Mandl C, Sugahara K, Faissner A (1998) The DSD-1 carbohydrate epitope depends on sulfation, correlates with chondroitin sulfate $\mathrm{D}$ motifs, and is sufficient to promote neurite outgrowth. J Biol Chem 273:28444-28453.

Deller T, Haas CA, Naumann T, Joester A, Faissner A, Frotscher M (1997) Up-regulation of astrocyte-derived Tenascin-C correlates with neurite outgrowth in the rat dentate gyrus after unilateral entorhinal cortex lesion. Neuroscience 81:829-846.

Dou CL, Levine JM (1994) Inhibition of neurite growth by the NG2 chondroitin sulfate proteoglycan. J Neurosci 14:7616-7628.

Dou CL, Levine JM (1995) Differential effects of glycosaminoglycans on neurite growth on laminin and L1 substrates. J Neurosci 15:8053-8066.

Emmerling DE, Lander AD (1996) Inhibitors and promoters of thalamic neuron adhesion and outgrowth in embryonic neocortex: functional association with chondroitin sulfate. Neuron 17:1089-1100.

Engel M, Maurel P, Margolis RU, Margolis RK (1996) Chondroitin sulfate proteoglycans in the developing central nervous system. I. Cellular sites of synthesis of neurocan and phosphacan. J Comp Neurol 366:34-43.

Faissner A (1988) Monoclonal antibody identifies a proteoglycan expressed by a subclass of glial cells. Soc Neurosci Abstr 14:920.

Faissner A, Steindler D (1995) Boundaries and inhibitory molecules in developing neural tissues. Glia 13:233-254.

Faissner A, Clement A, Lochter A, Streit A, Mandl C, Schachner M (1994) Isolation of a neural chondroitin sulfate proteoglycan with neurite outgrowth promoting properties. J Cell Biol 126:783-799.

Fernaud-Espinosa I, Nieto-Sampedro M, Bovolenta P (1994) Differential effects of glycosaminoglycans on neurite outgrowth from hippocampal and thalamic neurons. J Cell Sci 107:1437-1448.

Fichard A, Verna JM, Olivares J, Saxod R (1991) Involvement of a chondroitin sulfate proteoglycan in the avoidance of chick epidermis by dorsal root ganglion fibers: a study using $\beta$-D-xyloside. Dev Biol 148:1-9.

Fitch MT, Silver J (1997) Glial cell extracellular matrix: boundaries for axon growth in development and regeneration. Cell Tissue Res 290:379-384.

Gates MA, Thomas LB, Howard EM, Laywell ED, Sajin B, Faissner A, Götz B, Silver J, Steindler DA (1995) Cell and molecular analysis of the developing and adult mouse subventricular zone of the cerebral hemispheres. J Comp Neurol 361:249-266.

Golding J, Shewan D, Cohen J (1997) Maturation of the mammalian dorsal: root entry zone-from entry to no entry. Trends Neurosci 20:303-308.

Götz B, Scholze A, Clement A, Joester A, Schütte K, Wigger F, Frank R, Spiess P, Ekblom P, Faissner A (1996) Tenascin-C contains distinct 
adhesive, anti-adhesive, and neurite outgrowth promoting sites for neurons. J Cell Biol 132:681-699.

Grumet M, Flaccus A, Margolis RU (1993) Functional characterization of chondroitin sulfate proteoglycans of brain: interactions with neurons and neural cell adhesion molecules. J Cell Biol 120:815-824.

Hall H, Liu L, Schachner M, Schmitz B (1993) The L2/HNK-1 carbohydrate mediates adhesion of neural cells to laminin. Eur J Neurosci 5:34-43.

Hansen JE, Lund O, Engelbrecht J, Bohr H, Nielsen JO, Hansen JES, Brunak S (1995) Prediction of O-glycosylation of mammalian proteins: specificity patterns of UDP-GalNAc-polypeptide $N$-acetylgalactosaminyltransferase. Biochem J 308:801-813.

Heyman I, Faissner A, Lumsden A (1995) Cell and matrix specialisations of rhombomere boundaries. Dev Dyn 204:301-315.

Hockfield S, Kalb RG, Zaremba S, Fryer H (1990) Expression of neural proteoglycans correlates with the acquisition of mature neuronal properties in the mammalian brain. Cold Spring Harbor Symp Quant Biol 55:505-513.

Iijima N, Oohira A, Mori T, Kitabatake K, Kohsaka S (1991) Core protein of chondroitin sulfate proteoglycan promotes neurite outgrowth from cultured neocortical neurons. J Neurochem 56:706-708.

Katoh-Semba R, Matsuda M, Kato K, Oohira A (1995) Chondroitin sulphate proteoglycans in the rat brain: candidates for axon barriers of sensory neurons and the possible modification by laminin of their actions. Eur J Neurosci 7:613-621.

Keilhauer G, Faissner A, Schachner M (1985) Differential inhibition of neurone-neurone, neurone-astrocyte and astrocyte-astrocyte adhesion by L1, L2 and NCAM antibodies. Nature 316:728-730.

Kempf MA, Clement A, Faissner A, Lee G, Brandt R (1996) Tau binds to the distal axon early in development of polarity in a microtubuledependent manner. J Neurosci 16:5583-5592.

Kosaka T, Heizman CW, Fujita SC (1992) Monoclonal antibody 473 selectively stains a population of GABAergic neurons containing the calcium-binding protein parvalbumin in the rat cerebral cortex. Exp Brain Res 89:109-114.

Krueger NX, Saito H (1992) A human transmembrane protein-tyrosinephosphatase, PTP zeta, is expressed in brain and has an N-terminal receptor domain homologous to carbonic anhydrases. Proc Natl Acad Sci USA 89:7417-7421.

Kruse J, Mailhammer R, Wernecke H, Faissner A, Sommer I, Goridis C, Schachner M (1984) Neural cell adhesion molecules and myelinassociated glycoprotein share a common carbohydrate moiety recognised by monoclonal antibodies L2 and HNK-1. Nature 311:153-155.

Kruse J, Keilhauer G, Faissner A, Timpl R, Schachner M (1985) The J1 glycoprotein: a novel nervous system cell adhesion molecule of the L2/HNK-1 family. Nature 316:146-148.

Kücherer A, Faissner A, Schachner M (1987) The novel carbohydrate epitope L3 is shared by some neural adhesion molecules. J Cell Biol 104:1597-1602.

Kunemund V, Jungalwala FB, Fischer G, Chou DKH, Keilhauer G, Schachner M (1988) The L2/HNK-1 carbohydrate of neural cell adhesion molecules is involved in cell interactions. J Cell Biol 106:213-223.

Lafont F, Rouget M, Triller A, Prochiantz A, Rousselet A (1992) In vitro control of neuronal polarity by glycosaminoglycans. Development 114:17-29.

Lallier T, Bronner-Fraser M (1991) Avian neural crest cell attachment to laminin: involvement of divalent cation dependent and independent integrins. Development 113:1069-1084.

Lallier T, Leblanc G, Artinger KB, Bronner-Fraser M (1992) Cranial and trunk neural crest cells use different mechanisms for attachment to extracellular matrices. Development 116:531-541.

Lander AD (1993) Proteoglycans in the nervous system. Curr Opin Neurobiol 3:716-723.

Lander AD, Calof AL (1993) Extracellular matrix in the developing nervous system. In: Molecular genetics of nervous system tumors (Levine AJ, Schmidek HH, eds), pp 341-355. New York: Wiley-Liss.

Lander AD, Fujii DK, Reichardt LF (1985) Laminin is associated with the neurite outgrowth promoting factors found in conditioned media. Proc Natl Acad Sci USA 82:2183-2187.

Landholt RM, Vaughan L, Winterhalter KH, Zimmermann DR (1995) Versican is selectively expressed in embryonic tissues that act as barriers to neural crest cell migration and axon outgrowth. Development 121:2303-2312.

Laywell E, Faissner A, Schachner M, Silver J, Steindler DA (1990)
"Reexpression" of J1/tenascin and the 473 proteoglycan following discrete lesions in the adult mouse cerebral and cerebellar cortices. Soc Neurosci Abstr 16:163.

Laywell ED, Steindler DA (1991) Boundaries and wounds, glia and glycoconjugates. Ann NY Acad Sci 633:122-141.

Letourneau PC, Condic ML, Snow DM (1994) Interactions of developing neurons with the extracellular matrix. J Neurosci 14:915-928.

Lips K, Stichel C, Müller HW (1995) Restricted appearance of tenascin and chondroitin sulfate proteoglycans after transection and sprouting of rat postcommissural fornix. J Neurocytol 24:449-464.

Lochter A, Vaughn L, Kaplony A, Prochiantz A, Schachner M, Faissner A (1991) J1/tenascin in substrate-bound and soluble form displays contrary effects on neurite outgrowth. J Cell Biol 113:1159-1171.

Luckenbill-Edds L (1997) Laminin and the mechanism of neuronal outgrowth. Brain Res Rev 23:1-27.

Maeda N, Noda M (1996) 6B4 proteoglycan/phosphacan is a repulsive substratum but promotes morphological differentiation of cortical neurons. Development 122:647-658.

Maeda N, Hamanaka H, Oohira A, Noda M (1995) Purification, characterization and developmental expression of a brain-specific chondroitin sulfate proteoglycan, 6B4 proteoglycan/phosphacan. Neuroscience 67:23-35.

Maleski M, Hockfield S (1997) Glial cells assemble hyaluronan-based pericellular matrices in vitro. Glia 20:193-202.

Maurel P, Rauch U, Flad M, Margolis RK, Margolis RU (1994) Phosphacan, a chondroitin sulfate proteoglycan of brain that interacts with neurons and neural cell-adhesion molecules, is an extracellular variant of a receptor-type protein tyrosine phosphatase. Proc Natl Acad Sci USA 91:2512-2516.

McAdams BD, McLoon SC (1995) Expression of chondroitin sulfate and keratan sulfate proteoglycans in the path of growing retinal axons in the developing chick. J Comp Neurol 352:594-606.

McKeon RJ, Schreiber RC, Rudge JS, Silver J (1991) Reduction of neurite outgrowth in a model of glial scarring following CNS injury is correlated with the expression of inhibitory molecules on reactive astrocytes. J Neurosci 11:3398-3411.

Meyer-Puttlitz B, Milev P, Junker E, Zimmer I, Margolis RU, Margolis RK (1995) Chondroitin sulfate and chondroitin/keratan sulfate proteoglycans of nervous tissue: developmental changes of neurocan and phosphacan. J Neurochem 65:2327-2337.

Meyer-Puttlitz B, Junker E, Margolis RU, Margolis RK (1996) Chondroitin sulfate proteoglycans in the developing central nervous system. II. Immunocytochemical localization of neurocan and phosphacan. J Comp Neurol 366:44-54.

Milev P, Friedlander DR, Sakurai T, Karthikeyan L, Flad M, Margolis RK, Grumet M, Margolis RU (1994) Interactions of the chondroitin sulfate proteoglycan phosphacan, the extracellular domain of a receptor-type protein tyrosine phosphatase, with neurons, glia, and neural cell adhesion molecules. J Cell Biol 12:1703-1715.

Milev P, Meyer-Puttlitz B, Margolis RK, Margolis RU (1995) Complextype asparagine-linked oligosaccharides on phosphacan and proteintyrosine phosphatase-zeta/beta mediate their binding to neural cell adhesion molecules and tenascin. J Biol Chem 270:24650-24653.

Oakley RA, Tosney KW (1991) Peanut agglutinin and chondroitin-6sulfate are molecular markers for tissues that act as barriers to axon advance in the avian embryo. Dev Biol 147:187-206.

Oohira A, Matsui F, Katoh-Semba R (1991) Inhibitory effects of brain chondroitin sulfate proteoglycans on neurite outgrowth from PC12D cells. J Neurosci 11:822-827.

Peles E, Nativ M, Campbell PL, Sakurai T, Martinez R, Lev S, Clary DO, Schilling J, Barnea G, Plowman GD, Grumet M, Schlessinger J (1995) The carbonic anhydrase domain of receptor tyrosine phosphatase beta is a functional ligand for the axonal cell recognition molecule contactin. Cell 82:251-260.

Peles E, Nativ M, Lustig M, Grumet M, Schilling J, Martinez R, Plowman GD, Schlessinger J (1997) Identification of a novel contactinassociated transmembrane receptor with multiple domains implicated in protein-protein interactions. EMBO J 16:978-988.

Pindzola RR, Doller C, Silver J (1993) Putative inhibitory extracellular matrix molecules at the dorsal root entry zone of the spinal cord during development and after root and sciatic nerve lesions. Dev Biol 156:34-48.

Rauch U (1997) Modeling an extracellular environment for axonal pathfinding and fasciculation in the central nervous system. Cell Tissue Res 290:349-356. 
Rauch U, Gao P, Janetzko A, Flaccus A, Hilgenburg L, Tekotte H, Margolis RK, Margolis RU (1991) Isolation and characterisation of developmentally regulated chondroitin sulfate and chondroitin/keratan sulfate proteoglycans of brain identified with monoclonal antibodies. J Biol Chem 266:14785-14801.

Ring C, Lemmon V, Halfter W (1995) Two chondroitin sulfate proteoglycans differentially expressed in the developing chick visual system. Dev Biol 168:11-27.

Roberts C, Platt N, Streit A, Schachner M, Stern CD (1991) The L5 carbohydrate epitope: an early marker for neural induction in the chick embryo and its involvement in inductive interactions. Development 112:959-970.

Sakurai T, Friedlander DR, Grumet M (1996) Expression of polypeptide variants of receptor-type protein tyrosine phosphatase beta: the secreted form, phosphacan, increases dramatically during embryonic development and modulates glial cell behavior in vitro. J Neurosci Res 43:694-706.

Sakurai T, Lustig M, Nativ M, Hemperly J, Schlessinger J, Peles E, Grumet M (1997) Induction of neurite outgrowth through contactin and $\mathrm{Nr}-\mathrm{CAM}$ by extracellular regions of glial cell receptor tyrosine phosphatase $\beta$. J Cell Biol 136:907-918.

Schnädelbach O, Mandl C, Faissner A (1998) Expression of DSD-1-PG in primary neural and glial-derived cell line cultures, upregulation by TGF- $\beta$, and implications for cell-substrate interactions of the glial cell line Oli-neu. Glia 23:99-119.

Schwab ME, Kapf hammer JP, Bandtlow CE (1993) Inhibitors of neurite outgrowth. Annu Rev Neurosci 16:565-595.

Seilheimer B, Schachner M (1988) Studies of adhesion molecules mediating interactions between cells of peripheral nervous system indicating a major role of L1 in mediating sensory neuron growth on Schwann cells in culture. J Cell Biol 107:341-351.

Sheppard AM, Hamilton SK, Pearlman AL (1991) Changes in the distribution of extracellular matrix components accompany early morphogenetic events of mammalian cortical development. J Neurosci 11:3928-3942.

Smith-Thomas LC, Fok-Seang J, Stevens J, Du JS, Muir E, Faissner A,
Geller HM, Rogers JH, Fawcett JW (1994) An inhibitor of neurite outgrowth produced by astrocytes. J Cell Sci 107:1687-1695.

Snow DM, Lemmon V, Carrino DA, Caplan DA, Silver J (1990a) Sulfated proteoglycans in astroglial barriers inhibit neurite outgrowth in vitro. Exp Neurol 109:111-130.

Snow DM, Steindler DA, Silver J (1990b) Molecular and cellular characterisation of the glial roof plate of the spinal cord and optic tectum: a possible role for a proteoglycan in the development of an axon barrier. Dev Biol 138:359-376.

Snow DM, Brown EM, Letourneau PC (1996) Growth cone behavior in the presence of soluble chondroitin sulfate proteoglycan (CSPG) compared to behavior on CSPG bound to laminin or fibronectin. Int J Dev Neurosci 14:331-349.

Snyder SE, Li J, Schauwecker PE, McNeill TH, Salton SR (1996) Comparison of RPTP zeta/beta, phosphacan, and trkB mRNA expression in the developing and adult rat nervous system and induction of RPTP zeta/beta and phosphacan mRNA following brain injury. Mol Brain Res 40:79-96.

Steindler DA, Settles D, Erickson HP, Laywell ED, Yoshiki A, Faissner A, Kusakabe M (1995) Tenascin knockout mice: barrels, boundary molecules, and glial scars. J Neurosci 15:1971-1983.

Streit A, Faissner A, Gehrig B, Schachner M (1990) Isolation and biochemical characterization of a neural proteoglycan expressing the L5 carbohydrate epitope. J Neurochem 55:1494-1506.

Streit A, Nolte C, Rasony T, Schachner M (1993) Interaction of astrochondrin with extracellular matrix components and its involvement in astrocyte process formation and cerebellar granule cell migration. J Cell Biol 120:799-814.

Streit A, Yuen CT, Loveless RW, Lawson AM, Finne J, Schmitz B, Feizi T, Stern CD (1996) The Lewis-X carbohydrate sequence is recognised by antibody to L5, a functional antigen in early neural development. J Neurochem 66:834-844.

Wintergerst ES, Faissner A, Celio MR (1996) The proteoglycan DSD1-PG occurs in perineuronal nets around parvalbumin-immunoreactive interneurons of the rat cerebral cortex. Int J Dev Neurosci 14:249-255. 